FEDERAL RESERVE BANK OF SAN FRANCISCO

WORKING PAPER SERIES

\title{
Measuring the Effect of the Zero Lower Bound on Yields and Exchange Rates in the U.K. and Germany
}

\author{
Eric T. Swanson, \\ Federal Reserve Bank of San Francisco \\ John C. Williams, \\ Federal Reserve Bank of San Francisco
}

August 2013

Working Paper 2013-21

http://www.frbsf.org/publications/economics/papers/2013/wp2013-21.pdf

The views in this paper are solely the responsibility of the authors and should not be interpreted as reflecting the views of the Federal Reserve Bank of San Francisco or the Board of Governors of the Federal Reserve System. 


\title{
Measuring the Effect of the Zero Lower Bound on Yields and Exchange Rates in the U.K. and Germany
}

\author{
Eric T. Swanson* \\ and \\ John C. Williams* \\ Federal Reserve Bank of San Francisco
}

August 2013

\begin{abstract}
The zero lower bound on nominal interest rates began to constrain many central banks' setting of short-term interest rates in late 2008 or early 2009. According to standard macroeconomic models, this should have greatly reduced the effectiveness of monetary policy and increased the efficacy of fiscal policy. However, these models also imply that asset prices and private-sector decisions depend on the entire path of expected future short-term interest rates, not just the current level of the monetary policy rate. Thus, interest rates with a year or more to maturity are arguably more relevant for asset prices and the economy, and it is unclear to what extent those yields have been affected by the zero lower bound. In this paper, we apply the methods of Swanson and Williams (2013) to medium- and longer-term yields and exchange rates in the U.K. and Germany. In particular, we compare the sensitivity of these rates to macroeconomic news during periods when short-term interest rates were very low to that during normal times. We find that: 1) USD/GBP and USD/EUR exchange rates have been essentially unaffected by the zero lower bound, 2) yields on German bunds were essentially unconstrained by the zero bound until late 2012, and 3) yields on U.K. gilts were substantially constrained by the zero lower bound in 2009 and 2012, but were surprisingly responsive to news in 2010-11. We compare these findings to the U.S. and discuss their broader implications.
\end{abstract}

KEYWORDS: monetary policy, zero lower bound, forward guidance, fiscal policy, fiscal multiplier, exchange rates

JEL Classification: E43, E52, E62, F31, F42

\footnotetext{
*We thank our discussants, Domenico Giannone and Kenneth West, and Alain Chaboud, Richard Clarida, Michael Ehrmann, Charles Engel, Jeffrey Frankel, Refet Gürkaynak, James Hamilton, Kei Kawakami, Yvan Lengwiler, Benoit Mojon, John Taylor, Min Wei, Jonathan Wright, seminar participants at the 2013 NBER ISOM conference, and seminar participants at presentations of our earlier paper, "Measuring the Effect of the Zero Lower Bound on Mediumand Longer-Term Interest Rates," for helpful discussions, comments, and suggestions. We thank Maura Lynch and Kuni Natsuki for excellent research assistance. The opinions expressed in this paper are those of the authors and do not necessarily reflect the views of the people listed above, the Federal Reserve Bank of San Francisco, the Board of Governors of the Federal Reserve System, or any other individuals within the Federal Reserve System.

Swanson: Federal Reserve Bank of San Francisco, eric.swanson@sf.frb.org, http://www.ericswanson.org.

Williams: Federal Reserve Bank of San Francisco, 101 Market Street, San Francisco, CA 94105, Tel.: (415) 974-2121, John.C.Williams@sf.frb.org.
} 


\section{Introduction}

The recent global financial crisis led many central banks to reduce short-term interest rates to historic lows, making the zero lower bound on nominal interest rates a much greater concern than in the past. For example, the Federal Reserve lowered the federal funds rate to essentially zero in December 2008, and the Bank of England lowered Bank Rate to an effective lower bound near zero in early 2009. According to many macroeconomic models, the binding constraint of the zero lower bound on nominal interest rates should have greatly reduced the effectiveness of monetary policy and increased the efficacy of fiscal policy during this period (e.g., Christiano, Eichenbaum, and Rebelo 2011, Woodford 2011). ${ }^{1}$ However, standard macroeconomic theory, such as Woodford (2003) and Clarida, Galí, and Gertler (2002), as well as the papers cited above, imply that asset prices and the economy are affected by the entire path of expected future short-term interest rates, not just the current level of the short rate. Thus, interest rates with a year or more to maturity are of greater relevance than an overnight interest rate such as the federal funds rate, and it is not clear whether the zero lower bound has substantially constrained central banks' ability to affect these longer-term yields. ${ }^{2}$

In this paper, we apply the methodology of Swanson and Williams (2013) to estimate the effects of the zero lower bound on yields of various maturities and exchange rates in the United Kingdom and Germany. ${ }^{3}$ In particular, we estimate the time-varying sensitivity of bond yields and exchange rates in these countries to macroeconomic announcements using high-frequency data and

\footnotetext{
${ }^{1}$ See also Eggertsson (2009), Erceg and Lindé (2010), Eggertsson and Krugman (2012), and DeLong and Summers (2012). These authors emphasize that the macroeconomic effects of fiscal policy are much larger when the zero lower bound is binding, because in that case interest rates do not rise in response to higher output, and private investment and consumption are not "crowded out".

${ }^{2} \mathrm{~A}$ central bank can affect longer-term yields if it has the ability to commit to future values of the monetary policy rate, so that it can promise monetary accommodation in the future once the zero bound ceases to bind (Reifschneider and Williams 2000, Eggertsson and Woodford 2003). Empirically, Gürkaynak, Sack, and Swanson (2005a) find that Federal Reserve monetary policy announcements affect asset prices primarily through their effects on financial market expectations of future monetary policy, rather than changes in the current federal funds rate target. Central banks also may be able to affect longer-term yields through large-scale purchases of long-term bonds (e.g., Vayanos and Vila 2009, Hamilton and Wu 2012). See the discussion in Section 5, below, and in Swanson and Williams (2013).

${ }^{3}$ Although interest rates in Japan have been near the zero lower bound for many years, there are several practical difficulties that prevent us from considering Japan in the present paper. Most importantly, we do not have access to the surprise component of Japanese macroeconomic announcements or daily bond yield data that go back far enough to estimate the sensitivity of Japanese yields to macroeconomic announcements when the zero bound is not binding. (This is partly due to data availability and partly because the zero bound has been a potential constraint in Japan for so long, going back to the 1990s.) Moreover, the Japanese "bubble economy" of the 1980s and "lost decade" of the 1990s raise questions as to whether those periods represent normal bond yield behavior even if we did have data extending back that far.
} 


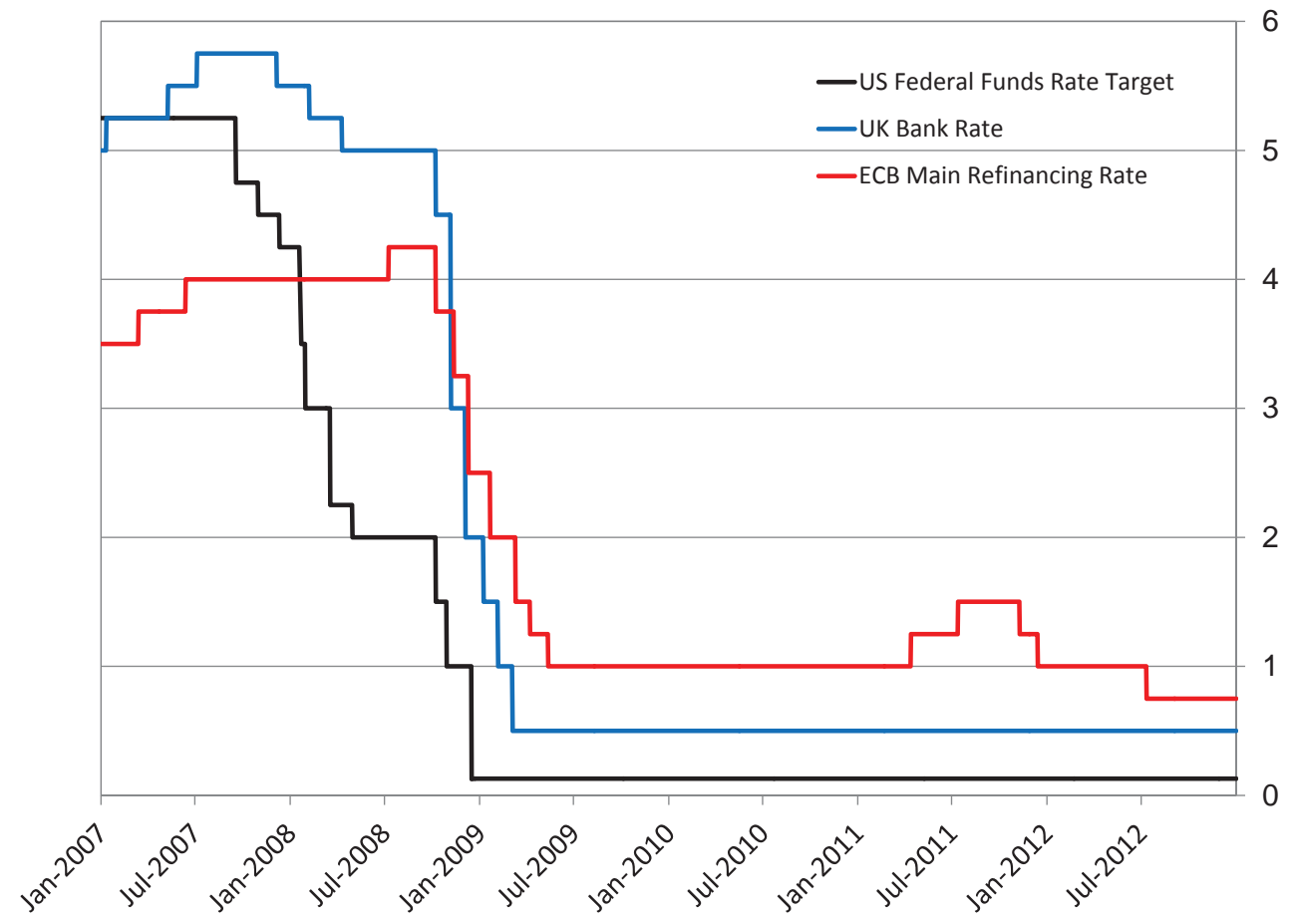

Figure 1. U.S. federal funds rate, U.K. Bank Rate, and European Central Bank (ECB) main refinancing rate from January 2007 through December 2012. All three policy rates declined sharply during the financial crisis, but the timing of these declines, and lowest level of rates reached, differs.

compare that sensitivity to a benchmark period in which the zero bound was not a concern. When a given interest or exchange rate is about as sensitive to news as in the benchmark sample, we say that rate is unconstrained. Alternatively, in periods when a given interest or exchange rate responds very little or not at all to news, we say that rate is largely or completely constrained. Intermediate cases are measured by the degree of the rate's sensitivity to news relative to the benchmark period, and the severity and statistical significance of the constraint can be assessed using standard econometric techniques.

Our results for the U.K. and Germany complement Swanson and Williams' (2013) findings for the U.S. in several respects. First, although U.K. and German monetary policy rates have fallen to historic lows, they have not fallen as low as in the United States (see Figure 1), so the timing and severity of the zero bound constraint in the United Kingdom and Germany is potentially different from that in the United States. Second, the U.K. and German economies are smaller than the U.S. economy and more dependent on international trade, which has important implications for the behavior of yields and exchange rates. For example, U.K. and German yields respond significantly to major U.S. macroeconomic announcements as well as to domestic announcements, while U.S. 
yields typically do not respond significantly to British or German data releases. Third, Swanson and Williams (2013) show that 1- and 2-year U.S. Treasury yields were quite sensitive to news throughout much of the 2008-11 period, and we find that this is the case for U.K. and German yields as well. Only beginning in late 2011 - around the time the Federal Reserve announced it expected to keep the funds rate at zero through "at least mid-2013" - do Swanson and Williams (2013) find that the sensitivity of intermediate-maturity U.S. Treasury yields fell close to zero, and we find this same result for the U.K., but not Germany. This is despite the lack of similar forward guidance from the Bank of England, suggesting that the Federal Reserve's "mid-2013" guidance may have affected monetary policy expectations in the U.K. as well as the U.S.

Fourth, despite the federal funds rate being essentially zero since December 2008, the USD/GBP and USD/EUR exchange rates have responded to news in much the same way as always, suggesting that the behavior of these exchange rates has been largely unaffected by the zero bound. Fifth and finally, although the Bank of England cut Bank Rate - its traditional monetary policy instrumentto 50 basis points (bp) in January 2009, it has since conducted large-scale asset purchases on a similar scale to the Federal Reserve, suggesting that $50 \mathrm{bp}$ is viewed as an effective lower bound on the U.K. monetary policy rate for institutional reasons. ${ }^{4}$ Thus, the U.K. provides an interesting test case of how our empirical methods perform when interest rates are constrained by an effective lower bound that is appreciably greater than zero.

It is important to note that the level of bond yields alone is not a good measure of whether they are constrained by the zero lower bound, for at least three reasons. First, simply looking at the level of a yield does not provide any insight into the severity of the zero bound constraint or its statistical significance. Figure 2 plots U.K. and German bond yields and monetary policy rates from the mid-1990s through the end of 2012. As seen in the figure, the one-year U.K. gilt yield dropped below $100 \mathrm{bp}$ in 2009, but there is no clear way to determine whether and to what extent that yield was constrained by the zero bound. Second, the lower bound on nominal interest rates may be above zero for institutional reasons, and this effective lower bound may vary across countries or over time, as in the example of the $50 \mathrm{bp}$ Bank Rate for the U.K., above. Third, the

\footnotetext{
${ }^{4}$ The Bank of England's web site reports that the Bank's Monetary Policy Committee "judged that Bank Rate could not practically be reduced below that level." See Bernanke and Reinhart (2004) for a discussion of the institutional barriers that might prevent lowering the policy rate all the way to zero.
} 
(a) U.K. Bank Rate and Zero-Coupon Gilt Yields

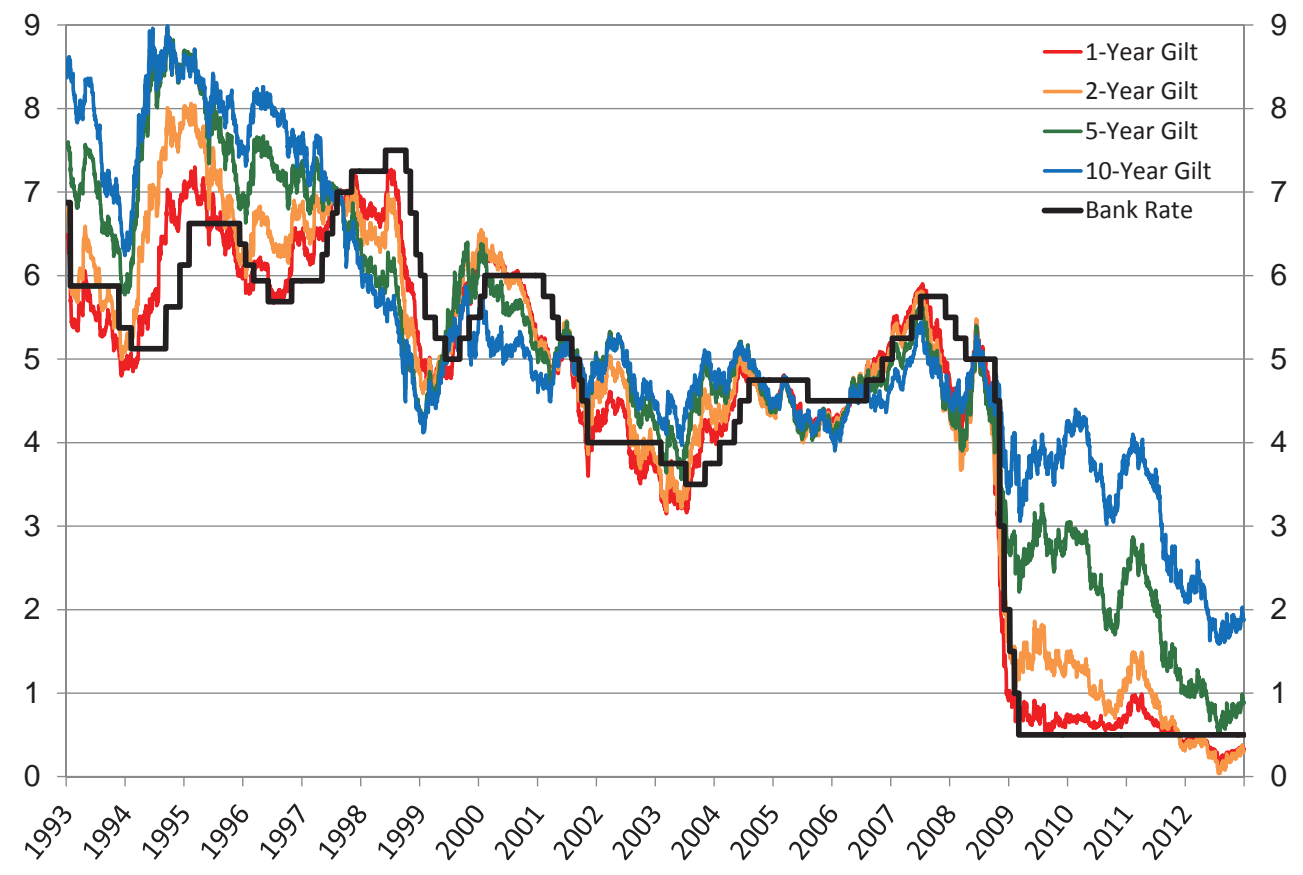

(b) German Lombard/Refinancing Rate and Zero-Coupon Bund Yields

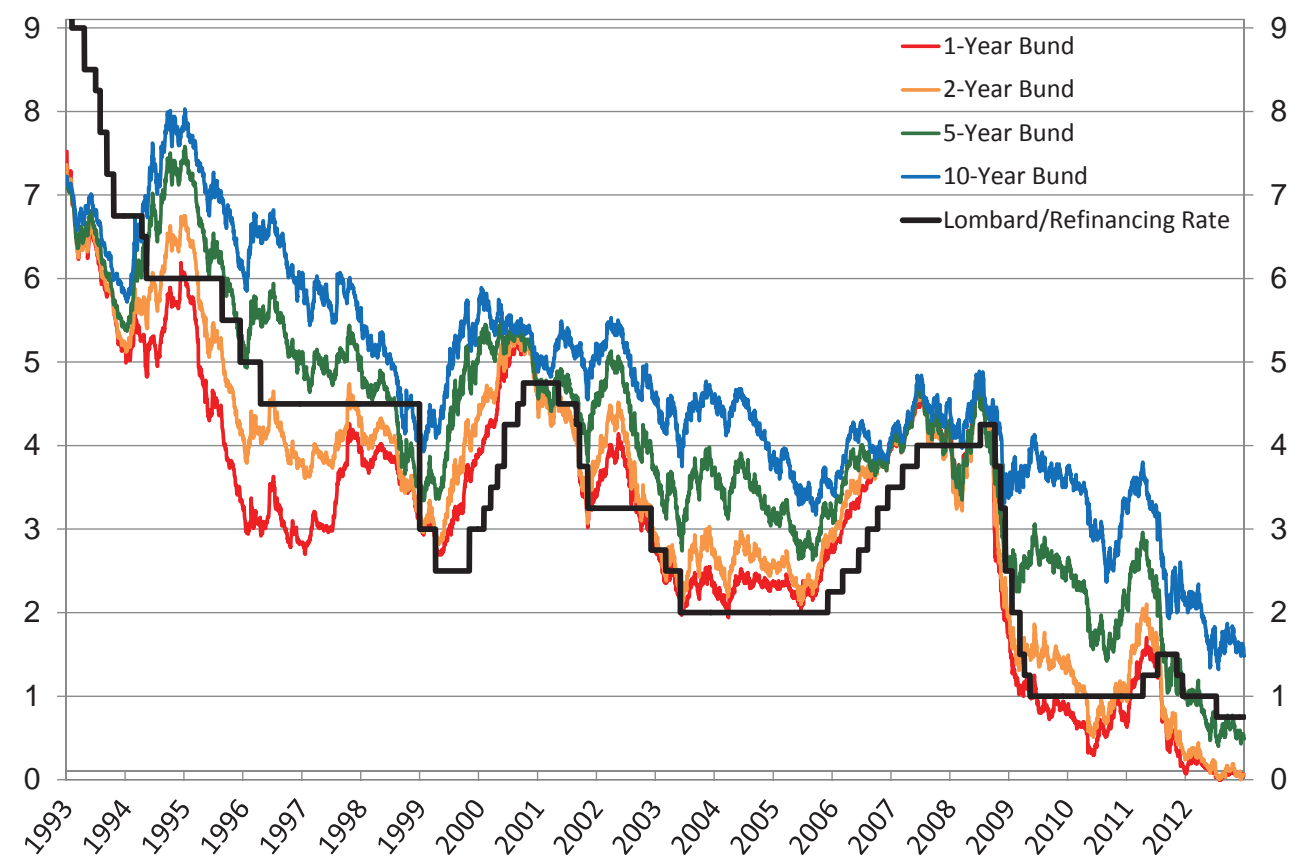

Figure 2. (a) U.K. Bank Rate and 1-, 2-, 5-, and 10-year zero-coupon gilt yields, and (b) German interbank rate and 1-, 2-, 5-, and 10-year zero-coupon bund yields from January 1993 through December 2012. The German interbank rate is the Lombard rate before January 1, 1999, and the ECB's main refinancing rate after that date. 
sensitivity of interest rates to news is more relevant than the level of yields for the fiscal multiplier. As emphasized by Christiano et al. (2011), Woodford (2011), and others, what is crucial for the fiscal multiplier is whether or not interest rates respond to a government spending shock; the level of yields by itself is largely irrelevant. Although the zero lower bound motivates the analysis in those studies, their results are all derived in a "constant interest rate" environment in which nominal yields can be regarded as fixed at any absolute level.

The approach in this paper does not depend on the level of rates, but rather relies on the sensitivity of interest rates to news. Therefore, it can accommodate effective lower bounds that may be greater than zero or change over time. In addition, the method provides an econometrically precise measure of the degree to which the zero lower bound is constraining medium- and longerterm yields and exchange rates.

Our analysis in the present paper proceeds as follows. Section 2 lays out a simple two-country New Keynesian model that helps motivate our empirical analysis and interpret our results. Section 3 describes our empirical methodology, which follows Swanson and Williams (2013). Section 4 reports

our empirical estimates of the sensitivity of bond yields and exchange rates in the U.K. and Germany to economic news. Section 5 considers the broader implications of our results and various extensions and robustness checks. Section 6 concludes. An Appendix provides a detailed description of the data used in our analysis.

\section{An Illustrative Model}

A simple theoretical model helps to motivate our empirical analysis and provides intuition for some of our empirical results. The purpose of this section is to illustrate qualitatively how the zero lower bound might be expected to affect the sensitivity of bond yields and exchange rates to news, so the model is deliberately simplistic and not intended to capture all the details of the effects we estimate below.

There are two countries, Home and Foreign. Analogous to a standard New Keynesian closedeconomy model (e.g., Woodford, 2003), Clarida, Galí, and Gertler (2002) show how a simple two- 
country New Keynesian model produces a standard forward-looking IS curve in the Home country,

$$
\tilde{y}_{t}=-\alpha\left(i_{t}-E_{t} \pi_{t+1}-r_{t}^{n}\right)+E_{t} \tilde{y}_{t+1},
$$

where $\tilde{y}_{t}$ denotes the output gap in the Home country in period $t, i_{t}$ the one-period Home nominal interest rate, $\pi_{t}$ the Home inflation rate, $r_{t}^{n}$ the Home "natural" rate of interest (which, as shown by Clarida, Galí, and Gertler (2002), depends on output in the Foreign economy as well as domestic factors), and $\alpha$ is a parameter. We model shocks to Home output as coming through shocks to $r_{t}^{n}$. Solving equation (1) forward, assuming $\lim _{j \rightarrow \infty} E_{t} \tilde{y}_{t+j}=0$, gives

$$
\tilde{y}_{t}=-\alpha E_{t} \sum_{j=0}^{\infty}\left[i_{t+j}-\pi_{t+j+1}-r_{t+j}^{n}\right] .
$$

Equation (2) makes it clear that the current level of the output gap depends on the entire expected future path of short-term interest rates (as well as inflation and the natural rate of interest), rather than just the current short-term interest rate. Thus, even if the current one-period interest rate is constrained by the zero lower bound, the effect of that constraint on the economy may be negligible if expectations of future short-term interest rates are unconstrained.

Analogous to a standard closed-economy model, Clarida, Galí, and Gertler (2002) also show that inflation in the Home country satisfies

$$
\pi_{t}=\beta E_{t} \pi_{t+1}+\gamma \tilde{y}_{t}+\mu_{t}
$$

where $\mu_{t}$ can be interpreted as a markup shock, and $\beta$ and $\gamma$ are parameters.

Together, equations (1) and (3) have the same form as a standard, one-country New Keynesian model. Following Swanson and Williams (2013), the one-period interest rate in the Home country is set according to a Taylor-type (1993) monetary policy rule, subject to the constraint that $i_{t}$ must be nonnegative:

$$
i_{t}=\max \left\{0, \pi_{t}+r_{t}^{n}+\theta_{\pi}\left(\pi_{t}-\bar{\pi}\right)+\theta_{y} \tilde{y}_{t}\right\}
$$

where $\bar{\pi}$ denotes the Home central bank's inflation target, and $\theta_{\pi}$ and $\theta_{y}$ are parameters. Note that monetary policy is assumed to respond to the current level of the natural interest rate. This implies that, absent the zero lower bound, monetary policy perfectly offsets the effects of shocks to the natural interest rate on the output gap and inflation. Of course, the presence of the zero lower bound implies that, in certain circumstances, monetary policy will be unable to offset such shocks. 
Together, equations (1)-(4) have the same structure as the one-country New Keynesian model considered in Swanson and Williams (2013). For a given choice of parameter values, the model can be solved numerically using the same methods as in that paper (see Reifschneider and Williams, 2000, for details), and produces essentially identical results for domestic variables in the Home country.

\subsection{The Sensitivity of Long-Term Bond Yields to News}

We use the above model to provide some basic intuition for the response of long-term bond yields to shocks when the zero lower bound is a constraint. Consistent with the log-linearized structure of the economy implicit in equations (1)-(3), long-term bond yields in the model are determined by the expectations hypothesis. ${ }^{5}$ Thus, the $M$-period yield to maturity, $i_{t}^{M}$, on a zero-coupon Home nominal bond is given by:

$$
i_{t}^{M}=E_{t} \sum_{j=0}^{M-1} i_{t+j}+\phi^{M},
$$

where $\phi^{M}$ denotes an exogenous term premium that may vary with maturity $M$ but is constant over time.

Using a simple one-country New Keynesian model, Swanson and Williams (2013) highlight three results that are relevant to our empirical analysis below. Because the structure of equations (1)-(5) above is essentially identical to the model in Swanson and Williams (2013), we do not reproduce those results in detail here, but instead briefly summarize them and refer interested readers to that paper for the details.

First, when short-term interest rates are constrained by the zero lower bound, yields of all maturities respond less to economic announcements than if the zero bound were not present; moreover, the reduction in the responsiveness of yields to news is greatest at short maturities and is smaller for longer-term yields. This result is intuitive: for the shortest maturities, there is a total lack of responsiveness to an output or inflation shock when the zero bound is binding. According to equation (5), longer-term yields are an average of expected future short-term interest rates over the

\footnotetext{
${ }^{5}$ The simplest intuition for the behavior of long-term bond yields is obtained by focusing on the expectations component of long-term bond yields rather than the term premium component, since risk premia on long-term bonds are not well understood. In addition, almost all of our empirical results below and in Swanson and Williams (2013) can be understood without resorting to a story about risk premia, which also helps motivate this modeling choice.
} 
life of the bond. Since the expected path of future short-term interest rates in the model converges back toward steady state over time, short-term interest rates are expected to be unconstrained by the zero lower bound at some point in the future. As a result, longer-term bond yields are not as attenuated as shorter-term yields in their sensitivity to news.

Second, the effects of the zero bound on the sensitivity of yields to news are approximately symmetric - that is, the responsiveness of yields to both positive and negative announcements falls by about the same amount when the zero bound is strongly binding on short-term rates. This implication of the model can be counterintuitive at first, since the zero bound is a one-sided constraint. Nevertheless, the intuition is clear: when the zero bound is strongly binding - that is, policymakers would like to set the one-period nominal interest rate substantially below zero for several periods - then short-term yields are completely unresponsive to both positive and negative shocks, as long as those positive shocks are not large enough to bring short-term rates above the zero bound. Longer-term yields are also about equally damped in response to positive and negative shocks because: (a) longer-term yields are an average of current and expected future short-term rates, (b) current short-term rates do not respond to either positive or negative shocks when the zero bound is binding, and (c) expected future short-term rates respond symmetrically to positive and negative shocks in periods in which the zero bound is not binding. There are very few periods in which expected future short-term rates are unconstrained by the zero bound for the positive shock but still constrained for the negative shock, and even in those periods the interest rate differential between the two cases is typically very small. These small differences are negligible compared to the response of the yield curve as a whole, so the result is almost perfectly symmetric. ${ }^{6}$ We also test this restriction in our empirical work below, and find that it is not rejected by the data.

Third, the zero lower bound attenuates the sensitivity of yields to news by similar amounts for different types of shocks, as long as the persistence of the effects of those shocks on shortterm interest rates is similar. Intuitively, the degree of attenuation across maturities is determined primarily by the length of time the zero bound is expected to bind, and not by the type of shock. If two different shocks in the model have persistent effects on short-term interest rates, then the

\footnotetext{
${ }^{6}$ This symmetry is perfect if the number of periods that policy is constrained by the zero bound does not change, which is the case for small shocks. Even for shocks that are very large by empirical standards, Swanson and Williams (2013) show that the response of yields in the model is essentially symmetric, for the reasons just discussed.
} 
attenuation across maturities is also approximately the same. In our empirical work below, we assume that the zero bound attenuates the sensitivity of the yield curve to news by the same amount for all shocks, although in the model above this would only be exactly true if all the shocks had identically persistent effects on the short-term interest rate. Empirically, these persistences are unlikely to be exactly the same, but we view this assumption as a reasonable approximation that can be tested, which we do below, and find that it is not rejected by the data.

\subsection{The Sensitivity of Exchange Rates to News}

We now consider the implications of the zero lower bound for the behavior of exchange rates in the model. Let $s_{t}$ denote the log of the nominal exchange rate, defined to be the price of Foreign currency in Home currency units. Arbitrage between foreign and domestic bonds implies that

$$
s_{t}=-\left(i_{t}-i_{t}^{*}\right)+E_{t} s_{t+1}+\psi_{t}
$$

where $i_{t}^{*}$ denotes the one-period Foreign nominal interest rate and $\psi_{t}$ is a risk premium adjustment that captures the fact that the arbitrage in (6) is risky. If $\psi_{t}=0$ for all $t$, then equation (6) describes the uncovered interest parity hypothesis (e.g., Engel, 2013).

Similar to equations (1)-(2), equation (6) implies that the exchange rate is related to the differential between long-term rather than short-term Home and Foreign interest rates. To see this, first rewrite equation (6) in terms of the real exchange rate, $q_{t} \equiv s_{t}+p_{t}^{*}-p_{t}$, where $p_{t}$ and $p_{t}^{*}$ denote the logs of the Home and Foreign price levels, respectively:

$$
q_{t}=-\left(i_{t}-i_{t}^{*}\right)+E_{t}\left(\pi_{t+1}-\pi_{t+1}^{*}\right)+E_{t} q_{t+1}+\psi_{t}
$$

Assuming the real exchange rate returns to purchasing power parity (or some other steady-state level) in the long run, we have $\lim _{j \rightarrow \infty} E_{t} q_{t+j}=\bar{q}$, for some $\bar{q}$. Then equation (7) can be solved forward, giving

$$
q_{t}=E_{t} \sum_{j=0}^{\infty}\left[-\left(i_{t+j}-i_{t+j}^{*}\right)+\left(\pi_{t+j+1}-\pi_{t+j+1}^{*}\right)+\psi_{t+j}\right]+\bar{q}
$$

Just as for the output gap in equation (2), equation (8) shows that the real exchange rate $q_{t}$ depends on the entire expected path of future short-term interest rate differentials, rather than just the current one-period differential. Thus, even if short-term interest rates in the Home or Foreign 
country are currently constrained by the zero lower bound, the effect of that constraint on the real exchange rate can be negligible if future short-term interest rates in the two countries are expected to be unconstrained.

For nominal exchange rates, assume that the current price levels in the Home and Foreign countries do not respond to a macroeconomic data release on the same day as the release itself. Then $p_{t}$ and $p_{t}^{*}$ can be regarded as fixed on the day of the announcement, so the response of $s_{t}$ and $q_{t}$ that day are identical. Thus, even if Home or Foreign short-term interest rates are constrained by the zero bound on date $t$, equation (8) implies that the nominal exchange rate can still respond essentially normally to news if short-term interest rates in the Home and Foreign countries are expected to be unconstrained by the zero bound within a few quarters.

\section{Empirical Framework}

We now seek to estimate the extent to which bond yields and exchange rates in the United Kingdom and Germany have been more or less sensitive to macroeconomic announcements over time. We do this in three steps: First, we identify the surprise component of major U.S., U.K., and German macroeconomic data releases. Second, we estimate the average sensitivity of any given bond yield (or exchange rate) to those announcements over a benchmark sample during which the zero bound was not a constraint on yields. Third, we compute the sensitivity of that same bond yield (or exchange rate) to news in later periods when the zero lower bound was constraining short-term interest rates and compare that sensitivity to the benchmark sample. Periods in which the zero bound was a significant constraint on a given yield or exchange rate should appear as periods of unusually low sensitivity of that asset to macroeconomic news. We first describe the data used in our analysis, and then describe the details of each of these three basic steps in turn.

\subsection{Bond Yield and Exchange Rate Data}

The Bank of England and the German Bundesbank provide daily estimates of yields on zerocoupon domestic government securities on their web sites. Zero-coupon yields strip out differences in coupon rates and fluctuations in effective bond duration that arise from changes in the level of 
interest rates. As a result, zero-coupon yields provide the cleanest measure of the interest rate at any given maturity across countries and over time. ${ }^{7}$ This is important in our analysis, because the level of interest rates varies substantially from the early 1990s through the end of 2012 (see Figure 2), which would cause the yield-to-maturity on coupon-bearing bonds to fluctuate over time.

The Bank of England's yield curve data begin in 1979 for most maturities. However, data for the shortest maturities - three and six months - have some significant gaps prior to 1997, especially for the three-month yield. For this reason, we exclude three-month U.K. yields from our analysis and even the results for six-month gilts should be treated with more caution than those for longer maturities. The Bank of England's daily bond yield data reflect the market close in London (about $4 \mathrm{pm}$ London time).

The Bundesbank's zero-coupon yield curve data begin on August 7, 1997. Prior to that date, we use daily zero-coupon yield curves for Germany from the Bank for International Settlements (BIS) that begin in $1983 .{ }^{8}$ The BIS data does not include German yields with maturity less than 1 year, and although the Bundesbank's yield curve data does include estimates as short as six months, the estimated 6 -month yields are very volatile. Thus, the shortest bund yield maturity we include in our analysis is the 1-year yield. The Bundesbank and BIS data are based on daily price quotes for German government securities at noon Frankfurt time, which implies that any response to U.S. macroeconomic data releases (which occur at about 2:30pm Frankfurt time) will not show up until the quote for the next business day. Thus, care must be taken in our regression analysis, below, to account for the difference in timing across the U.S. and German macroeconomic announcements.

For exchange rates, we obtained daily data on the dollar-pound, dollar-euro, and dollardeutschemark rates from the Bank of England and Bundesbank web sites, respectively. Daily changes in the exchange rate for Germany are taken to be the daily change in the (log) dollardeutschemark rate prior to January 1, 1999, and the daily change in the (log) dollar-euro rate after that date. Quotes for all three exchange rates are 4pm London time, so the U.S. macroeconomic announcement data is known to the markets on the same day it is released in the U.S.

\footnotetext{
${ }^{7}$ See Gürkaynak, Sack, and Wright (2007) for additional discussion regarding zero-coupon yields.

${ }^{8}$ These data are from BIS database series HGLA.DE, numbers 14 through 32.
} 


\subsection{The Surprise Component of Macroeconomic Announcements}

Financial markets are by their nature forward-looking, so the expected component of macroeconomic announcements should have essentially no effect on interest rates, exchange rates, or other asset prices. ${ }^{9}$ To measure the effects of major macroeconomic data releases on interest rates, then, we first compute the unexpected, or surprise, component of each release.

As in Gürkaynak et al. (2005b), we compute the surprise component of each announcement as its realized value less the financial markets' expectation for that value from a few days before. We obtained data on financial market expectations of major U.S., British, and German macroeconomic data releases from two sources: Bloomberg Financial Services and Money Market Services (MMS). Both Bloomberg and MMS conduct surveys of financial market institutions and professional forecasters about their expectations for upcoming major data releases, and we take the median survey response as our measure of the financial market expectation. An important feature of these surveys is that they are conducted just a few days prior to each announcement - the MMS survey is conducted the Friday before each data release and the Bloomberg survey can be updated by participants up until the night before the release - so these forecasts should reflect essentially all relevant information up to a few days (or even the night before) the release. Andersen et al. (2003) and other authors have verified that these data pass standard tests of forecast rationality and provide a reasonable measure of ex ante expectations of the data release, which we have verified over our sample as well.

Bloomberg survey data are available to us up to the present, but do not begin until 1996 or 1997 for most series. Data from MMS go back further, to about 1990 for most major U.S. macroeconomic announcements, 1993 for most British announcements, and 1995 for most German announcements. When the Bloomberg and MMS survey data overlap, they agree very closely, since they are surveying essentially the same set of financial institutions and professional forecasters. In our regressions below, we give priority to the Bloomberg data when they are available because they in principle incorporate all information up through the night before each release.

We begin our analysis of the U.K. on Jan. 1, 1993, because of the lack of survey expectations

\footnotetext{
${ }^{9}$ Kuttner (2001) tests and confirms this hypothesis for the case of monetary policy announcements in the U.S. Andersen et al. (2003) discuss and test this fact for the case of exchange rates.
} 
data prior to that date. An additional reason to begin our U.K. sample in 1993 is a potential structural break in the behavior of gilt yields in late 1992, when the U.K. abandoned the European Exchange Rate Mechanism (ERM) and adopted an inflation targeting framework for monetary policy. ${ }^{10}$ For Germany, we begin our analysis on Jan. 1, 1995, because of the lack of expectations data prior to that date. (We also tried beginning our sample for Germany on Jan. 1, 1999, when the euro was introduced, but this made essentially no difference for our empirical results.) For both the U.K. and Germany, we end our sample on December 31, 2012.

Interest rates and exchange rates in the U.K. and Germany respond to major U.S. macroeconomic announcements as well as to domestic announcements. Thus, our regressions for interest rates and exchange rates in both countries include measures of the surprise component of major U.S. macroeconomic data releases. A detailed description of each of the U.S., U.K., and German macroeconomic data releases included in our analysis is provided in the Appendix.

\subsection{The Sensitivity of Yields and Exchange Rates to Macroeconomic News}

In normal times - when bond yields are far above the zero lower bound-those yields typically respond to major macroeconomic announcements. To measure this responsiveness, Gürkaynak et al. (2005b) and Swanson and Williams (2013) estimate daily-frequency regressions of the form

$$
\Delta y_{t}=\alpha+\beta X_{t}+\varepsilon_{t},
$$

where $t$ indexes days, $\Delta y_{t}$ denotes the one-day change in the bond yield over the day, $X_{t}$ is a vector of surprise components of macroeconomic data releases that took place that day, and $\varepsilon_{t}$ is a residual representing the influence of any other news or any other factors affecting that bond yield on that day. Regression (9) also can be applied to other assets such as the exchange rate, as in Andersen et al. (2003) and Faust et al. (2007), in which case $\Delta y_{t}$ denotes the one-day (log) percentage change in the exchange rate on date $t$. Note that most macroeconomic data series, such as U.S. nonfarm payrolls or U.K. average earnings, are released only once per month, so on days for which there is no news about a particular macroeconomic series, we set the corresponding element of $X_{t}$ equal to

\footnotetext{
${ }^{10}$ Gürkaynak, Levin, and Swanson (2010) provide a detailed discussion of how the U.K.'s switch to inflation targeting relates to the behavior of longer-term gilt yields.
} 


\begin{tabular}{|c|c|c|c|c|c|c|}
\hline \multirow[b]{3}{*}{ UK Average Earnings } & \multicolumn{6}{|c|}{ U.K. Gilt Yield Maturity } \\
\hline & \multicolumn{2}{|c|}{ 6-month } & \multicolumn{2}{|c|}{ 2-year } & \multicolumn{2}{|c|}{ 10-year } \\
\hline & 1.83 & $(4.36)$ & 2.53 & $(4.69)$ & 1.02 & $(2.39)$ \\
\hline UK GDP (advance) & 0.49 & $(1.09)$ & 1.56 & $(2.35)$ & 1.19 & $(2.40)$ \\
\hline UK Manufacturing Prod. & 0.26 & $(0.61)$ & 1.66 & $(4.90)$ & 1.09 & $(2.70)$ \\
\hline UK PPI & 0.72 & $(2.58)$ & 0.88 & $(2.43)$ & 0.87 & $(2.28)$ \\
\hline UK Retail Sales & 1.23 & $(4.10)$ & 2.16 & $(4.73)$ & 0.40 & $(0.85)$ \\
\hline UK RPIX & 1.67 & $(4.53)$ & 2.74 & $(4.63)$ & 1.66 & $(3.43)$ \\
\hline UK Unemployment & -0.36 & $(-1.10)$ & -1.14 & $(-2.55)$ & 0.07 & $(0.16)$ \\
\hline US Capacity Utilization & 0.07 & $(0.22)$ & 1.14 & $(2.77)$ & 0.92 & $(2.08)$ \\
\hline US Core CPI & 0.94 & $(3.25)$ & 1.02 & $(2.70)$ & 0.73 & $(1.90)$ \\
\hline US GDP (advance) & -0.58 & $(-1.46)$ & 0.03 & $(0.05)$ & -0.45 & $(-0.55)$ \\
\hline US Initial Claims & -0.04 & $(-0.23)$ & -0.55 & $(-2.97)$ & -0.68 & $(-3.50)$ \\
\hline US ISM Manufacturing & 0.94 & $(3.66)$ & 2.05 & $(5.41)$ & 2.63 & $(6.07)$ \\
\hline US Nonfarm Payrolls & 0.73 & $(2.93)$ & 1.90 & $(3.92)$ & 1.81 & $(3.42)$ \\
\hline US Core PPI & 0.11 & $(0.56)$ & 0.58 & $(1.77)$ & 0.44 & $(1.41)$ \\
\hline US Retail Sales ex. Autos & 0.27 & $(0.96)$ & 0.59 & $(1.16)$ & 1.04 & $(1.96)$ \\
\hline US Unemployment Rate & 0.64 & $(1.66)$ & 0.80 & $(1.36)$ & 1.42 & $(2.42)$ \\
\hline \# Observations & \multicolumn{2}{|c|}{1796} & \multicolumn{2}{|c|}{1912} & \multicolumn{2}{|c|}{1912} \\
\hline & \multicolumn{2}{|c|}{.05} & \multicolumn{2}{|c|}{.10} & \multicolumn{2}{|c|}{.06} \\
\hline$H_{0}: \beta=0, p$-value & \multicolumn{2}{|c|}{$<10^{-15}$} & \multicolumn{2}{|c|}{$<10^{-16}$} & \multicolumn{2}{|c|}{$<10^{-15}$} \\
\hline
\end{tabular}

Table 1. Coefficient estimates $\beta$ from linear regression $\Delta y_{t}=\alpha+\beta X_{t}+\varepsilon_{t}$ of U.K. gilt yields at daily frequency on days of announcements from Jan. 1993 to Dec. 2006. Change in yields $\Delta y_{t}$ is in basis points; surprise component of macroeconomic announcements $X_{t}$ are normalized by their historical standard deviations, so coefficients represent a basis point per standard deviation response. Heteroskedasticity-consistent $t$-statistics in parentheses. $H_{0}: \beta=0 p$-value is for the test that all elements of $\beta$ are zero. See text for details.

zero. $^{11}$

Table 1 demonstrates regression (9) by applying it to the 6-month, 2-year, and 10-year U.K. gilt yields from January 1993 through December 2006, a period when U.K. short-term interest rates were far above zero and hence the zero lower bound was almost certainly not a constraint (see Figure 2). Each of the three main columns in Table 1 represents a separate regression of the corresponding gilt yield on U.S. and U.K. macroeconomic data releases listed at the left. Both the U.S. and U.K. announcements have highly statistically significant effects on gilt yields (and the exchange rate, not shown in this table). We also experimented with including German macroeconomic announcements in these regressions as well, but they did not have a significant effect on U.K. yields

\footnotetext{
${ }^{11}$ Thus, if we write $X$ as a matrix with columns corresponding to macroeconomic series and rows corresponding to time $t$, each column of $X$ will be a vector consisting mostly of zeros, with one nonzero value per month corresponding to the surprise component of the announcement on the date it was released.
} 
and are thus excluded for simplicity. The three regressions in Table 1 exclude days on which no major macroeconomic data was released (i.e., days on which $X_{t}$ is identically zero), although the results are very similar whether or not these non-announcement days are included. To facilitate interpretation of the coefficients in Table 1, each macroeconomic data release surprise series is normalized by its historical standard deviation. ${ }^{12}$ Thus, coefficients in the table are in units of basis points per standard-deviation surprise in the announcement.

The first column of Table 1 reports results for the 6-month U.K. gilt yield. Positive surprises in output or inflation generally cause the 6-month yield to rise, consistent with a Taylor-type reaction function for U.K. monetary policy. The 6-month yield typically responds more to domestic announcements than it does to U.S. announcements, suggesting that the domestic data are more relevant for the U.K. economy and monetary policy than are the U.S. data. It is also true that U.S. announcements have a larger effect on U.S. yields than they do on U.K. yields, which can be seen by comparing the results here to Swanson and Williams' (2013) Table 1, and suggests that the U.S. data are more relevant for U.S. yields than they are for U.K. yields. The release with the largest effect on the 6-month gilt yield is U.K. average earnings, for which a one-standard-deviation surprise causes yields to move by about $1.8 \mathrm{bp}$ on average, with a $t$-statistic greater than 4 . Taken together, the 16 data releases in Table 1 provide us with about 1800 observations that have an extremely statistically significant effect on the 6-month yield, with a joint $F$-statistic above 11 and a $p$-value less than $10^{-15}$.

The results for 2- and 10-year gilt yields in the second and third columns are similar, with joint statistical significance levels that are also extremely high. The response of the 2-year yield to news is often larger than the response of the 6-month and 10-year yields. which implies that the response of the yield curve to news tends to be hump-shaped. ${ }^{13}$ There are about a hundred more observations for these longer-term yields than for the 6-month yield because the Bank of England's yield curve data contains some gaps prior to 1997 at the shorter maturities.

Comparable results for German yields are not reported in this section but are similar. That is,

\footnotetext{
${ }^{12}$ These historical standard deviations are reported in the Appendix, along with other details for each series.

${ }^{13}$ This is consistent with the standard result in monetary policy VARs that short-term interest rates have a humpshaped response to output and inflation shocks (e.g., Sims and Zha 1999), and the finding that estimated monetary policy rules display inertia, so that the central bank responds only gradually to news (e.g., Sack and Wieland, 2000). For simplicity, we considered a noninertial monetary policy rule in the previous section, but the key observations from that model are essentially unchanged if an inertial policy rule is used instead.
} 
German and U.S. macroeconomic announcements have an extremely statistically significant effect on German yields, with the signs of the coefficients corresponding to what one would expect from a Taylor-type reaction function for monetary policy and a hump-shaped response of interest rates to macroeconomic news.

Overall, the high-frequency regressions in Table 1 provide us with a great deal of information with which to estimate the sensitivity of bond yields (and exchange rates) to macroeconomic news. ${ }^{14}$ The large number of observations and the extraordinary statistical significance of the regressions gives them a high degree of power to estimate potential time-variation in the sensitivity of these assets to news, to which we now turn.

\subsection{Measuring Time-Varying Sensitivity of Yields and Exchange Rates}

In principle, one can measure the time-varying sensitivity of Treasury yields to news by running regression (9) over one-year rolling windows. However, this approach suffers from small-sample problems because most macroeconomic series have data releases only once per month, providing just twelve observations per year with which to estimate each element of the vector $\beta$.

Swanson and Williams (2013) overcome this small-sample problem by imposing that the relative magnitudes of the elements of $\beta$ are constant over time, so that only the overall magnitude of $\beta$ varies as the yield in question becomes more or less affected by the presence of the zero lower bound. Intuitively, if a Treasury security's sensitivity to news is reduced because its yield is starting to run up against the zero bound, then we expect that security's responsiveness to all macroeconomic data releases to be damped by a roughly proportional amount. This assumption is supported by the illustrative model in Section 2 and by empirical tests we conduct below.

Thus, for each given Treasury yield, we generalize regression (9) to a nonlinear least squares

\footnotetext{
${ }^{14}$ Although the magnitudes of the coefficients in Table 1 are only a few basis points per standard deviation and the $R^{2}$ no more than 0.1 , these results should not be too surprising given the low signal-to-noise ratio of any single monthly data release for the true underlying state of economic activity and inflation. There are several reasons for this. For example, our surprise data cover only the headline component of each announcement, while the full releases are much richer: e.g., the U.S. employment report includes not just nonfarm payrolls and the unemployment rate, but also how much of the change in payrolls is due to government hiring, how much of the change in unemployment is due to workers dropping out of the labor force, and revisions to the previous two nonfarm payrolls announcements. The situation is very similar for all of the other releases in Table 1, and details such as these typically have a substantial effect on the markets' overall interpretation of a release. The important point to take away from Table 1 is that the large number of observations and extraordinary statistical significance of the regressions implies that they are extremely informative about the sensitivity of Treasury yields to economic news.
} 
specification of the form:

$$
\Delta y_{t}=\gamma^{\tau_{i}}+\delta^{\tau_{i}} \beta X_{t}+\varepsilon_{t},
$$

where the parameters $\gamma^{\tau_{i}}$ and $\delta^{\tau_{i}}$ are scalars that are allowed to take on different values in each calendar year $i=1993,1994, \ldots, 2012(1995, \ldots, 2012$ for Germany). The reason for the notation $\gamma^{\tau_{i}}, \delta^{\tau_{i}}$ rather than $\gamma^{i}, \delta^{i}$ will become clear shortly. The use of annual dummies in (10) is deliberately atheoretical at this stage in order to "let the data speak"; we will consider higher-frequency and more structural explanations for the time-varying sensitivity coefficients $\delta$ in Section 5, below. Note that regression (10) greatly reduces the small-sample problem associated with allowing every element of $\beta$ to vary across years, because in (10) there are about 140 observations of $\beta X_{t}$ per year with which to estimate and identify each scalar $\delta^{\tau_{i}}$.

We must choose a normalization in order to separately identify the coefficients $\beta$ and $\delta^{\tau_{i}}$ in (10). We normalize the $\delta^{\tau_{i}}$ so that they have an average value of unity from 1993-2006 (19952006 for Germany), which is a period when short-term interest rates in the U.K. and Germany were substantially above zero and thus were almost certain to be unconstrained by the zero lower bound (see Figure 2). An estimated value of $\delta^{\tau_{i}}$ close to one thus represents a year in which the bond yield (or exchange rate) behaved normally in response to news, while an estimated value of $\delta^{\tau_{i}}$ close to zero corresponds to a year in which the bond yield (or exchange rate) was completely unresponsive to news. Intermediate values of $\delta^{\tau_{i}}$ correspond to years in which the asset's sensitivity to news was partially attenuated.

To provide finer estimates of the periods when each asset's sensitivity to news was attenuated, we also estimate daily rolling regressions of the form

$$
\Delta y_{t}=\gamma^{\tau}+\delta^{\tau} \hat{X}_{t}+\varepsilon_{t}^{\tau}
$$

where $\hat{X}_{t} \equiv \hat{\beta} X_{t}$ denotes a "generic surprise" regressor defined using the estimated value of $\hat{\beta}$ from (10), and (11) is estimated over one-year rolling windows centered around each business day $\tau$ from 1993 through 2012 (1995 through 2012 for Germany). ${ }^{15}$ When $\tau$ corresponds to the midpoint of a given calendar year $i \in\{1993,1994, \ldots, 2012\}$, the estimated value of the attenuation coefficient

\footnotetext{
${ }^{15}$ Toward either end of our sample, the regression window gets truncated and thus becomes smaller and less centered, approaching a six-month leading window in January 1993 (January 1995 for Germany) and a six-month trailing window in December 2012.
} 
$\delta^{\tau}$ agrees exactly with $\delta^{\tau_{i}}$ from regression (10). But we can also estimate (11) for any business day $\tau$ in our sample, and plot the coefficients $\delta^{\tau}$ over time $\tau$ to provide a finer estimate of the periods during which each bond yield's (or exchange rate's) sensitivity to news was attenuated. When we plot the standard errors in regression (11) around the point estimates for $\delta^{\tau}$, we account for the two-stage sampling uncertainty by using the estimated standard errors of the $\delta^{\tau_{i}}$ from regression (10) as benchmarks and interpolating between them using the standard errors estimated in (11). ${ }^{16}$

\section{Results}

We now apply the above methods to estimate the time-varying sensitivity of bond yields and exchange rates in the U.K. and Germany to major macroeconomic announcements. We focus in this section on the basic empirical results themselves, and defer discussion of their broader implications to the next section.

\section{$4.1 \quad$ U.K. Gilts}

Table 2 reports nonlinear least squares estimates for $\beta$ in regression (10) for the 6-month, 2-year, and 10-year U.K. gilt yields over the full sample from January 1993 through December 2012. The period from 1993 to 2006 is taken to be the benchmark sample over which $\delta^{\tau}$ is normalized to have an average value of unity. During that period, U.K. Bank Rate and gilt yields never fell below 3 percent (see Figure 2); as a result, the zero lower bound should have had essentially no effect on U.K. yields and their sensitivity to news should be viewed as normal on average.

The results in Table 2 are similar to those in Table 1, with coefficients having comparable signs and magnitudes and the overall statistical significance of the regressions being similarly high. At the bottom of Table 2, we report results for three specification tests of the nonlinear least squares regression (10). First, we test the hypothesis that the relative response coefficients $\beta$ in (10) are constant over time - and only the scalar sensitivity coefficients $\delta^{\tau_{i}}$ vary-against an alternative in

\footnotetext{
${ }^{16}$ Nonlinear least squares regression (10) is a one-stage regression whose standard errors are estimated consistently and efficiently under standard econometric assumptions. Thus, we use these standard errors for $\delta^{\tau_{i}}$ as benchmarks. Let $\sigma^{\tau}$ denote the OLS standard error for $\delta^{\tau}$ on date $\tau$ from daily rolling regression (11) (which ignores the sampling uncertainty for $\hat{\beta}$ ). Let $\varsigma^{\tau_{i}}$ denote the benchmark standard errors for $\delta^{\tau_{i}}$ from NLS regression (10). For $\tau$ between benchmark dates $\tau_{i}$ and $\tau_{i+1}$, we scale up $\sigma^{\tau}$ by a factor of $\frac{\tau_{i+1}-\tau}{\tau_{i+1}-\tau_{i}} \cdot \frac{\varsigma^{\tau_{i}}}{\sigma^{\tau_{i}}}+\frac{\tau-\tau_{i}}{\tau_{i+1}-\tau_{i}} \cdot \frac{\varsigma^{\tau_{i+1}}}{\sigma^{\tau_{i+1}}}$.
} 
U.K. Gilt Yield Maturity

\begin{tabular}{|c|c|c|c|c|c|c|}
\hline \multirow[b]{2}{*}{ UK Average Earnings } & \multicolumn{2}{|c|}{ 6-month } & \multicolumn{2}{|c|}{ 2-year } & \multicolumn{2}{|c|}{ 10-year } \\
\hline & 2.28 & $(5.73)$ & 2.90 & $(5.79)$ & 0.71 & $(1.59)$ \\
\hline UK GDP (advance) & 0.69 & $(1.39)$ & 3.17 & $(3.44)$ & 1.21 & $(2.38)$ \\
\hline UK Manufacturing Prod. & 0.42 & $(1.14)$ & 1.10 & $(3.87)$ & 0.60 & $(1.24)$ \\
\hline UK PPI & 1.00 & $(2.98)$ & 1.40 & $(2.48)$ & 1.28 & $(2.63)$ \\
\hline UK Retail Sales & 0.92 & $(2.94)$ & 1.69 & $(4.96)$ & 0.70 & $(1.52)$ \\
\hline UK RPIX & 1.48 & $(5.20)$ & 2.23 & $(4.33)$ & 1.71 & $(4.30)$ \\
\hline UK Unemployment & -0.23 & $(-0.80)$ & -1.29 & $(-2.76)$ & -0.16 & $(-0.48)$ \\
\hline US Capacity Utilization & 0.29 & $(1.02)$ & 1.51 & $(3.32)$ & 0.90 & $(1.93)$ \\
\hline US Core CPI & 0.62 & $(1.71)$ & 0.67 & $(1.86)$ & 0.88 & $(2.18)$ \\
\hline US GDP (advance) & -0.68 & $(-1.70)$ & 0.48 & $(0.92)$ & -0.82 & $(-0.97)$ \\
\hline US Initial Claims & -0.08 & $(-0.61)$ & -0.63 & $(-3.79)$ & -0.64 & $(-3.10)$ \\
\hline US ISM Manufacturing & 1.04 & $(3.98)$ & 1.57 & $(5.27)$ & 2.52 & $(5.92)$ \\
\hline US Nonfarm Payrolls & 0.47 & $(1.81)$ & 1.58 & $(3.58)$ & 1.60 & $(3.25)$ \\
\hline US Core PPI & 0.31 & $(1.40)$ & 0.77 & $(2.19)$ & 0.56 & $(1.43)$ \\
\hline US Retail Sales ex. autos & 0.58 & $(2.56)$ & 0.96 & $(2.28)$ & 1.34 & $(2.62)$ \\
\hline US Unemployment rate & 0.27 & $(0.66)$ & 0.28 & $(0.67)$ & 1.01 & $(1.92)$ \\
\hline \# Observations & \multicolumn{2}{|c|}{2592} & \multicolumn{2}{|c|}{2708} & \multicolumn{2}{|c|}{2708} \\
\hline$R^{2}$ & \multicolumn{2}{|c|}{.08} & \multicolumn{2}{|c|}{.11} & \multicolumn{2}{|c|}{.06} \\
\hline$H_{0}: \beta=0, p$-value & \multicolumn{2}{|c|}{$<10^{-13}$} & \multicolumn{2}{|c|}{$<10^{-16}$} & \multicolumn{2}{|c|}{$<10^{-15}$} \\
\hline$H_{0}: \beta$ constant, $p$-value & \multicolumn{2}{|c|}{1.000} & \multicolumn{2}{|c|}{1.000} & \multicolumn{2}{|c|}{1.000} \\
\hline$H_{0}: \delta$ symmetric, $p$-value & \multicolumn{2}{|c|}{.904} & \multicolumn{2}{|c|}{.169} & \multicolumn{2}{|c|}{.099} \\
\hline$H_{0}: \delta$ constant, $p$-value & \multicolumn{2}{|c|}{$<10^{-16}$} & \multicolumn{2}{|c|}{$<10^{-16}$} & \multicolumn{2}{|c|}{.003} \\
\hline
\end{tabular}

Table 2. Coefficient estimates $\beta$ from nonlinear regression $\Delta y_{t}=\gamma^{\tau_{i}}+\delta^{\tau_{i}} \beta X_{t}+\varepsilon_{t}$ at daily frequency on days of announcements from Jan. 1993 to Dec. 2012. Coefficients indexed $\tau_{i}$ may take on different values in different calendar years. $\Delta y_{t}$ and $X_{t}$ are as in Table 1 . Heteroskedasticityconsistent $t$-statistics in parentheses. $H_{0}: \beta$ constant tests whether $\beta$ is fixed over time and only the $\delta^{\tau_{i}}$ vary. $H_{0}: \delta$ symmetric tests whether $\delta^{\tau_{i}}$ is the same for positive and negative surprises $\beta X_{t}$. $H_{0}: \delta$ constant tests whether $\delta^{\tau_{i}}=1$ for all years $i$. See notes to Table 1 and text for details.

which every element of $\beta$ is permitted to vary independently in every calendar year, that is:

$$
\Delta y_{t}=\gamma^{\tau_{i}}+\beta^{\tau_{i}} X_{t}+\varepsilon_{t}
$$

As can be seen in Table 2, there is essentially no loss in fit from using (10) rather than (12), relative to the degrees of freedom of the restriction; the $p$-values are all equal to 1 to three decimal places. ${ }^{17}$ The assumption of a constant $\beta$ in (10) is thus very consistent with the data.

Second, we test the hypothesis that the $\delta^{\tau_{i}}$ in (10) are the same for positive and negative

\footnotetext{
${ }^{17}$ The Wald statistics for these hypothesis tests are 41.2, 32.5, and 30.3 for the 6-month, 2-year, and 10-year gilt yields, respectively, with 285 degrees of freedom for each test. Thus, the losses in fit are very small relative to the degrees of freedom of the restriction.
} 
surprises $\beta X_{t}$, against an alternative in which we allow separate attenuation coefficients $\delta_{+}^{\tau_{i}}$ and $\delta_{-}^{\tau_{i}}$ for positive and negative values of $\beta X_{t}$ in each calendar year $i$. In other words, we separate the data into two groups - those announcements that have positive implications for yields, and those that have negative implications - and test whether the attenuation coefficients $\delta_{+}^{\tau_{i}}=\delta_{-}^{\tau_{i}}$ for each $i=1993, \ldots, 2012 .^{18}$ As can be seen in Table 2, this restriction is also not rejected by the data, with $p$-values typically well above ten percent (although it does fall to 9.9 percent for the 10-year yield). We conclude that this restriction is also consistent with the data.

Third, we test the hypothesis that the time-varying sensitivity coefficients $\delta^{\tau_{i}}$ in (10) are constant over time. That is, we test whether $\delta^{\tau_{i}}=1$ for each calendar year $i=1993, \ldots, 2012$. In contrast to the previous two tests, here the data strongly reject the restriction. For the 6-month and 2-year gilt yields, the $p$-values are less than $10^{-16}$. Clearly, the sensitivity of these two yields to macroeconomic news has varied substantially over time. The constant- $\delta$ restriction for the 10year yield is also rejected, although not quite as strongly, with a $p$-value of .003. Although the 10-year yield's sensitivity to news does appear to have varied over time, the assumption of constant sensitivity for this yield is not nearly as inconsistent with the data as for the shorter-maturity yields.

In Figure 3, we plot the time-varying sensitivity coefficients $\delta^{\tau}$ from regression (10) as a function of time $\tau$, using the daily rolling regression specification (11) to interpolate between the annual benchmarks $\delta^{\tau_{i}}$. The six panels of the figure depict results for the 6-month and 1-, 2-, 3-, 5-, and 10-year zero-coupon gilt yields, respectively. The solid blue line in each panel plots the estimated value of $\delta^{\tau}$ on each date $\tau$, while the dotted gray lines depict heteroskedasticityconsistent \pm 2 -standard-error bands, adjusted for the two-stage estimation procedure as described in the preceding section. In each panel, horizontal black lines are drawn at 0 and 1 as benchmarks for comparison, corresponding to the cases of complete insensitivity to news and normal sensitivity, respectively.

In each panel, the regions shaded yellow denote periods when the estimated value of $\delta^{\tau}$ is significantly less than unity at the five percent level. In addition, if the hypothesis $\delta^{\tau}=0$ cannot be

\footnotetext{
${ }^{18}$ The first group consists of all of the U.K. unemployment and U.S. initial claims surprises (and, in some cases, U.S. GDP) that are less than zero, and all of the positive surprises in the other statistics. The second group consists of all of the unemployment and initial claims surprises (and, in some cases, U.S. GDP) that are greater than zero, and all of the negative surprises in the other statistics.
} 

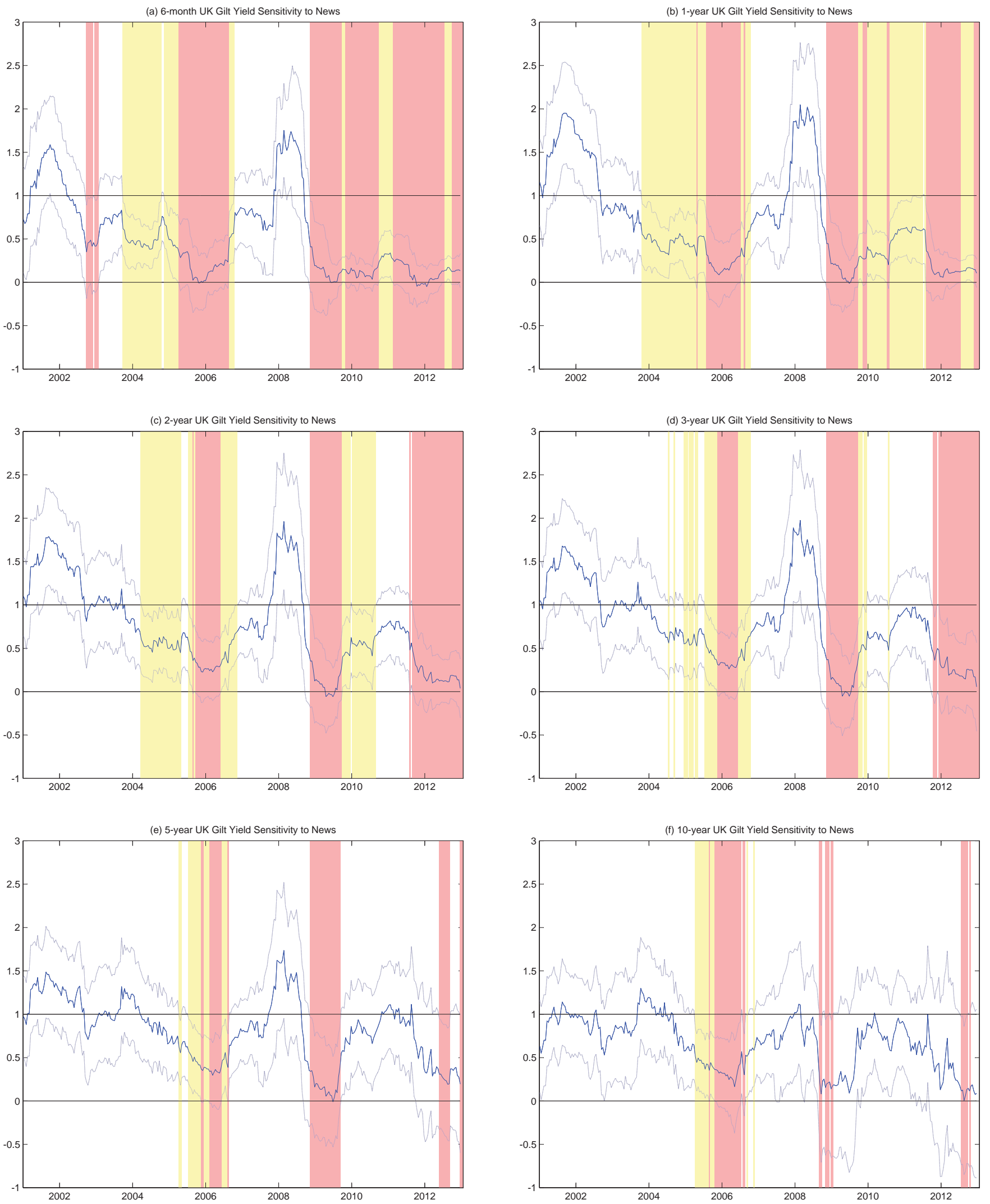

Figure 3. Time-varying sensitivity coefficients $\delta^{\tau}$ from regression (11) for (a) 6-month, (b) 1-year, (c) 2-year, (d) 3-year, (e) 5-year, and (f) 10-year U.K. gilt yields. Dotted gray lines depict heteroskedasticityconsistent \pm 2 -standard-error bands, adjusted for two-stage sampling uncertainty in $(11)$. $\delta^{\tau}=1$ corresponds to normal sensitivity to news; $\delta^{\tau}=0$ to complete insensitivity. Yellow shaded regions denote $\delta^{\tau}$ significantly less than 1; red shaded regions denote $\delta^{\tau}$ significantly less than 1 and not significantly different from 0 . See text for details. 
rejected at the five percent level, then the region is shaded red. Thus, red shaded regions correspond to periods in which the gilt yield was essentially insensitive to news, while yellow shaded regions correspond to periods in which the yield was partially — but not completely - unresponsive to news.

Panel (a) of Figure 3 shows that the sensitivity of the 6-month gilt yield to macroeconomic news has varied between about 0 and 1.5 from 2001 through 2012. From the beginning of 2009 through the end of 2012, the 6-month yield was either partially or completely insensitive to news. It is natural to interpret this insensitivity as being caused by the zero lower bound, since the 6-month gilt yield was essentially zero from December 2008 through the end of our sample, and the U.K. Bank Rate was at its effective lower bound of 50bp. At the shortest end of the U.K. yield curve, at least, interest rates appear to have been substantially constrained by the zero bound from the spring of 2009 onward.

What is perhaps more surprising in the first panel of Figure 3 is that the 6-month yield was also partially or completely insensitive to news between 2004 and mid-2006, a period during which Bank Rate and the 6-month gilt yield never fell below 3 percent. We note this episode now but defer a detailed exploration and discussion until the next section. ${ }^{19}$

Panel (b) of Figure 3 reports analogous results for the 1-year gilt. The sensitivity of the 1-year yield to macroeconomic news ranges between 0 and 2, and is close to zero in 2009 and from late 2011 through the end of our sample. Interestingly, the 1-year gilt's sensitivity to news picks up to a more normal level in 2010 and 2011, suggesting that the zero bound was less of a constraint during that period. Like the 6-month yield, the 1-year yield also displays reduced sensitivity to news from 2004 to mid-2006.

Results for 2- and 3-year gilts are reported in the middle panels of Figure 3. The sensitivity of these intermediate-maturity yields to news is less attenuated than that of the 6-month and 1-year yields throughout the sample. For example, the 2- and 3-year yields behave close to normally in 2010-11, suggesting that the zero bound was not much of a constraint on their behavior during that period. The 2- and especially 3-year yields' sensitivity to news is also closer to normal in 2004-05.

The bottom two panels of Figure 3 report results for the 5- and 10-year gilts. The 5-year

\footnotetext{
${ }^{19}$ Between 1993 and 2001, there are no other periods in which the 6-month or other gilt yields display reduced sensitivity to news (that is, there are no red- or yellow-shaded regions in the period before 2001, which isn't plotted in Figure 3). Thus, the 2004-2006 period is very unusual.
} 
yield is insensitive to news in early- to mid-2009, but both yields respond normally from late 2009 through the end of 2011, suggesting that the zero bound was not a constraint on their behavior during this latter period. Beginning in late 2011, the sensitivity of these yields to news declines again, but the standard errors are large enough that this period of reduced sensitivity is often not statistically significant. The 5 - and 10 -year yields behave essentially normally in $2004-05$, but there is a brief period from late 2005 to early 2006 where their sensitivity to news is lower than normal.

\subsection{German Bunds}

Table 3 reports nonlinear least squares estimates for $\beta$ in regression (10) for the 1-, 2-, and 10-year German bund yields over the full sample for Germany, January 1995 through December 2012. The period from 1995 to 2006 is taken to be the benchmark sample over which $\delta^{\tau}$ is normalized to have an average value of unity. During that period, the German Lombard rate, ECB refinancing rate, and German bund yield never fell below 2 percent (see Figure 2), so the zero lower bound should not have been a constraint on German yields and their sensitivity to news can be viewed as relatively normal.

German interest rates tend to increase in response to positive news about output (particularly the IFO business conditions survey and domestic retail sales), consistent with a Taylor-type reaction function for monetary policy. However, German yields do not respond significantly to news about domestic inflation. This lack of response may result from the national inflation data in Germany being released later than various state-level inflation measures (see Andersson et al., 2006, and Ehrmann et al., 2011). In contrast, German yields do respond significantly to U.S. core CPI and PPI announcements, as well as to many of the other major U.S. data releases, with upward surprises in U.S. output and inflation tending to cause German interest rates to rise. In contrast, German yields do not respond significantly to U.K. announcements, so those data are excluded from the regressions in Table 3 for simplicity.

The response of German yields to domestic macroeconomic announcements is more muted than was the case for the U.K. in Table 2, but the sensitivity to U.S. announcements in Tables 2 and 3 is similar. As Andersson et al. (2006) discuss, the relatively low sensitivity of German yields to domestic announcements may be due to the German data being released with a longer lag than 


\begin{tabular}{|c|c|c|c|c|c|c|}
\hline Ger. CPI & -0.33 & $(-1.15)$ & -0.21 & $(-0.74)$ & -0.37 & $(-1.28)$ \\
\hline Ger. GDP & -0.14 & $(-0.33)$ & -0.44 & $(-0.63)$ & -0.15 & $(-0.22)$ \\
\hline Ger. IFO Bus. Survey & 0.97 & $(4.92)$ & 1.57 & $(5.44)$ & 1.54 & $(4.95)$ \\
\hline Ger. Retail Sales & 0.68 & $(2.22)$ & 0.89 & $(2.28)$ & 0.33 & $(0.90)$ \\
\hline Ger. Unemployment & -0.24 & $(-1.03)$ & -0.62 & $(-2.02)$ & -0.05 & $(-0.19)$ \\
\hline US Capacity Utilization & 0.24 & $(1.23)$ & 0.78 & $(4.00)$ & 0.63 & $(1.86)$ \\
\hline US Core CPI & 0.61 & $(2.15)$ & 0.87 & $(2.28)$ & 0.82 & $(2.39)$ \\
\hline US GDP (advance) & 1.09 & $(2.08)$ & 1.63 & $(2.67)$ & 0.66 & $(1.17)$ \\
\hline US Initial Claims & -0.70 & $(-4.46)$ & -0.92 & $(-5.15)$ & -0.86 & $(-5.37)$ \\
\hline US ISM Manufacturing & 1.05 & $(4.84)$ & 1.20 & $(4.15)$ & 1.23 & $(4.31)$ \\
\hline US Nonfarm Payrolls & 1.30 & $(2.65)$ & 2.05 & $(2.97)$ & 2.12 & $(3.98)$ \\
\hline US Core PPI & 0.18 & $(0.90)$ & 0.52 & $(2.03)$ & 0.77 & $(2.49)$ \\
\hline US Retail Sales ex. autos & 0.98 & $(3.66)$ & 1.34 & $(3.92)$ & 1.23 & $(3.59)$ \\
\hline US Unemployment rate & -0.15 & $(-0.61)$ & -0.11 & $(-0.33)$ & -0.47 & $(-1.36)$ \\
\hline \# Observations & \multicolumn{2}{|c|}{2419} & \multicolumn{2}{|c|}{2419} & \multicolumn{2}{|c|}{2419} \\
\hline$R^{2}$ & \multicolumn{2}{|c|}{.07} & \multicolumn{2}{|c|}{.09} & \multicolumn{2}{|c|}{.06} \\
\hline$H_{0}: \beta=0, p$-value & \multicolumn{2}{|c|}{$<10^{-9}$} & \multicolumn{2}{|c|}{$<10^{-15}$} & \multicolumn{2}{|c|}{$<10^{-12}$} \\
\hline$H_{0}: \beta$ constant, $p$-value & \multicolumn{2}{|c|}{1.000} & \multicolumn{2}{|c|}{1.000} & \multicolumn{2}{|c|}{1.000} \\
\hline$H_{0}: \delta$ symmetric, $p$-value & \multicolumn{2}{|c|}{.944} & \multicolumn{2}{|c|}{.845} & \multicolumn{2}{|c|}{.023} \\
\hline$H_{0}: \delta$ constant, $p$-value & \multicolumn{2}{|c|}{$<10^{-9}$} & \multicolumn{2}{|c|}{$<10^{-10}$} & \multicolumn{2}{|c|}{.009} \\
\hline
\end{tabular}

Table 3. Coefficient estimates $\beta$ from nonlinear regression $\Delta y_{t}=\gamma^{\tau_{i}}+\delta^{\tau_{i}} \beta X_{t}+\varepsilon_{t}$ at daily frequency on days of announcements from Jan. 1995 to Dec. 2012 for 1-, 2-, and 10-year German bunds. See notes to Table 2 and text for details.

the U.S. data, which may reduce the informativeness of the German data for financial markets. Nevertheless, the regressions in Table 3 have an extraordinary degree of statistical significance, with $p$-values less than $10^{-9}, 10^{-15}$, and $10^{-12}$ for the $1-, 2$, and 10-year yields, respectively.

The bottom three rows of Table 3 consider the same specification tests as in Table 2, with similar results. First, the hypothesis that $\beta$ is constant over time is again very consistent with the data - there is essentially no loss in fit from using (10) rather than (12), relative to the degrees of freedom of the restriction. ${ }^{20}$ Second, the hypothesis that $\delta^{\tau_{i}}$ in (10) is symmetric for positive and negative surprises $\beta X_{t}$ is not rejected by the data for the 1- and 2-year yields, although it is rejected for the 10-year yield. However, that rejection is due to the rapid decline in yields in 1995 rather than the zero bound period at the end of our sample. ${ }^{21}$ Thus, the hypothesis that $\delta^{\tau_{i}}$ is

\footnotetext{
${ }^{20}$ The Wald statistics for these tests are 16.5, 26.9, and 37.2 for the 1-, 2-, and 10-year bunds, respectively, with 204 degrees of freedom for each test. Thus, the loss in fit is very small relative to the degrees of freedom of the restriction.

${ }^{21}$ If we begin our sample in 1996 instead of 1995, the hypothesis that $\delta^{\tau_{i}}$ is symmetric for positive and negative surprises has a $p$-value of .128. Moreover, the estimated $\delta_{+}^{\tau_{i}}$ coefficient in 1995 is lower than the $\delta_{-}^{\tau_{i}}$ coefficient-in
} 

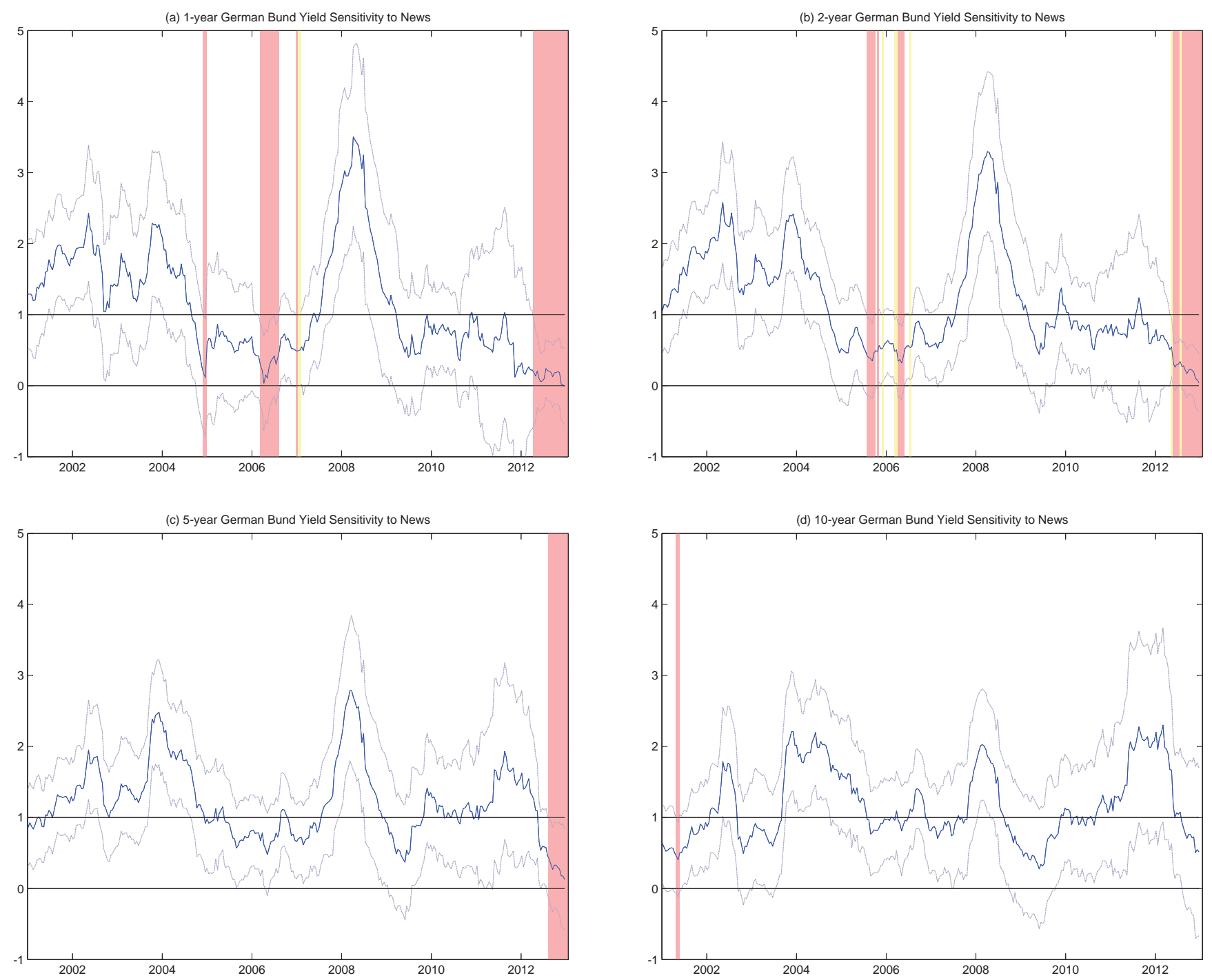

Figure 4. Time-varying sensitivity coefficients $\delta^{\tau}$ from regression (11) for (a) 1-year, (b) 2-year, (c) 5-year, and (d) 10-year German bund yields. See notes to Figure 3 and text for details.

symmetric also seems to be generally consistent with the German data. Third, the hypothesis that the $\delta^{\tau_{i}}$ in (10) are constant over time is strongly rejected, with $p$-values less than $10^{-9}$ and $10^{-10}$ for the 1- and 2-year yields, and .009 for the 10-year yield. Although the 10-year yield's sensitivity to news does seem to have varied over time, the assumption of constant sensitivity for this yield is not as inconsistent with the data as it is for the shorter-maturity yields.

Figure 4 plots the time-varying sensitivity coefficients $\delta^{\tau}$ for rolling regression (11) applied to the 1-, 2-, 5-, and 10-year German bund yields, analogous to Figure 3. Yellow and red shaded other words, negative data surprises caused the 10-year yield to fall, while positive surprises did not cause the 10-year yield to rise by as much. This is consistent with the strong decline in German yields in 1995 (see Figure 2), but is exactly opposite the effect the zero lower bound would have if it were leading to an asymmetry. 
regions are defined in the same was as in Figure 3, with yellow regions denoting periods when the given yield is significantly less than unity but significantly greater than zero, and red shaded regions denoting periods when the given yield is significantly less than unity and not significantly greater than zero.

In panel (a) of Figure 4, the sensitivity of the 1-year yield to macroeconomic news ranges between 0 and about 3.5 over our sample, with the maximum reached during the financial crisis in 2008. This variation in sensitivity is larger than for U.K. gilts, whose sensitivity roughly doubled in 2008, but is more comparable to the increase in sensitivity of 1- and 2-year U.S. Treasuries, which rose to about 2.5 in 2008 (see Swanson and Williams, 2013). Thus, the higher sensitivity in Germany during this period is not dramatically different from the U.S. or U.K., especially given the standard errors around these estimates; moreover, the sensitivity of 5- and 10-year German bunds rises by about the same amount as 5- and 10-year yields in the U.K. and U.S.

The 1-year bund yield's sensitivity to news drops to almost zero for a brief period in 2006, but as a whole behaves in a mostly unconstrained manner in 2004-06. In contrast to our estimates for

the 1-year U.K. gilt yield in Figure 3, here the 1-year bund's sensitivity to news remains close to normal throughout 2009-11, suggesting that the German 1-year yield was relatively unconstrained by the zero bound (or other factors) over this period. Only around the second half of 2012 - after the ECB cut its policy rate to 0.75 percent - does the 1-year bund's sensitivity to news fall to essentially zero, suggesting that only then did markets begin to view that yield as being constrained.

Results for the 2-year bund are reported in the second panel of Figure 4 and are very similar. The sensitivity of the 2-year yield to news is essentially normal until mid-2012, at which point it begins to respond to news in a more constrained manner. The behavior of 5- and 10-year bund yields in the bottom two panels of Figure 4 is even less constrained. Only at the very end of 2012 does the 5-year yield become less sensitive to news, while the 10-year yield is not significantly attenuated at any point in our sample.

\subsection{U.K. and German Exchange Rates}

Regressions (10) and (11) can also be applied to exchange rates - or to any other asset price - to measure how their sensitivity to news varies over time. We now apply these regressions to the 


\begin{tabular}{|c|c|c|c|c|}
\hline Ger. CPI & -.037 & $(-0.21)$ & -.022 & $(-0.62)$ \\
\hline Ger. GDP & -.083 & $(-0.78)$ & .102 & $(1.20)$ \\
\hline Ger. IFO Business Survey & .092 & $(2.30)$ & .172 & $(3.52)$ \\
\hline Ger. Retail Sales & .018 & $(0.41)$ & -.002 & $(-0.04)$ \\
\hline Ger. Unemployment & -.018 & $(-0.86)$ & -.011 & $(-0.30)$ \\
\hline UK Average Earnings & .084 & $(2.69)$ & -.015 & $(-0.35)$ \\
\hline UK GDP (advance) & .293 & $(4.11)$ & .003 & $(0.07)$ \\
\hline UK Manufacturing Prod. & .033 & $(1.43)$ & .046 & $(1.10)$ \\
\hline UK PPI & .097 & $(3.22)$ & .056 & $(1.95)$ \\
\hline UK Retail Sales & .126 & $(4.02)$ & -.004 & $(-0.09)$ \\
\hline UK RPIX & .052 & $(0.98)$ & .019 & $(0.47)$ \\
\hline UK Unemployment claims & .023 & $(0.65)$ & .107 & $(1.39)$ \\
\hline US Capacity Utilization & -.056 & $(-1.35)$ & -.054 & $(-1.15)$ \\
\hline US Core CPI & .013 & $(0.41)$ & .044 & $(1.13)$ \\
\hline US GDP (advance) & -.109 & $(-1.55)$ & -.267 & $(-4.18)$ \\
\hline US Initial Claims & -.016 & $(-1.12)$ & .005 & $(0.27)$ \\
\hline US ISM Manufacturing & -.077 & $(-2.17)$ & -.135 & $(-3.67)$ \\
\hline US Nonfarm Payrolls & -.158 & $(-4.27)$ & -.172 & $(-3.88)$ \\
\hline US Core PPI & .047 & $(1.84)$ & .116 & $(2.78)$ \\
\hline US Retail Sales ex. autos & -.042 & $(-1.43)$ & -.052 & $(-1.50)$ \\
\hline US Unemployment rate & .099 & $(2.71)$ & .039 & $(0.82)$ \\
\hline \# Observations & \multicolumn{2}{|r|}{2801} & \multicolumn{2}{|c|}{2794} \\
\hline$R^{2}$ & \multicolumn{2}{|r|}{.04} & \multicolumn{2}{|c|}{.04} \\
\hline$H_{0}: \beta=0, p$-value & \multicolumn{2}{|c|}{$<10^{-7}$} & \multicolumn{2}{|c|}{$<10^{-5}$} \\
\hline$H_{0}: \beta$ constant, $p$-value & \multicolumn{2}{|c|}{1.000} & \multicolumn{2}{|c|}{1.000} \\
\hline$H_{0}: \delta$ symmetric, $p$-value & \multicolumn{2}{|r|}{.005} & \multicolumn{2}{|c|}{.307} \\
\hline$H_{0}: \delta$ constant, $p$-value & \multicolumn{2}{|c|}{$<.001$} & \multicolumn{2}{|c|}{.002} \\
\hline
\end{tabular}

Table 4. Coefficient estimates $\beta$ from nonlinear regression $\Delta y_{t}=\gamma^{\tau_{i}}+\delta^{\tau_{i}} \beta X_{t}+\varepsilon_{t}$ at daily frequency on days of announcements from Jan. 1995 to Dec. 2012 for USD/GBP and USD/DMEUR exchange rates. Change in exchange rate is measured as $100 * \log$ change, so coefficients represent percent change per standard deviation surprise in the announcement. DM-EUR denotes deutschemark up to Jan. 1, 1999, and euro afterward. See notes to Table 2 and text for details.

USD/GBP and USD/DM-EUR exchange rates to explore whether they have been significantly affected by the zero lower bound on interest rates.

Table 4 reports nonlinear least squares estimates for $\beta$ in regression (10) for the USD/GBP and USD/DM-EUR exchange rates over the full sample for which we have German data, January 1995 through December 2012. The benchmark sample for these regressions, over which the $\delta^{\tau_{i}}$ are normalized to have an average value of unity, is taken to be the period up through 2006, just as for the bond yield regressions in Tables 2 and 3. The left-hand side variable in each regression is 100 
times the one-day change in the logarithm of the exchange rate, so coefficients in the table are in units of percent change per standard deviation surprise in the announcement. The USD/DM-EUR exchange rate is defined to be the dollar price of the deutschemark prior to Jan. 1, 1999, and the dollar price of the euro after that date.

The USD/GBP exchange rate responds positively, on average, to upward surprises in British output and inflation - that is, the pound tends to appreciate in response to these surprises. Conversely, the pound tends to depreciate in response to upward surprises in U.S. output. These coefficients are generally consistent with the theoretical analysis in Section 2, in which surprises that imply an increase in domestic interest rates tend to appreciate the domestic currency, and surprises that imply an increase in foreign interest rates tend to depreciate it. The German IFO business survey - an important indicator of German output - has a positive effect on the pound, suggesting that markets regard good news about German output as being more positive for U.K. interest rates than for U.S. rates. News about British GDP has the largest effect on the pound, with a one-standard-deviation surprise leading to a 0.3 percent appreciation. The $R^{2}$ of the regression is low, at just 4 percent, consistent with the standard finding that exchange rate movements are difficult to explain with fundamentals (e.g., Andersen et al., 2003). The regression nevertheless has an extremely high degree of statistical significance overall, with a $p$-value less than $10^{-7}$, owing to the large number of observations and the fact that exchange rates do respond systematically to many of the macroeconomic announcements in the table (Andersen et al., 2003).

Results for the USD/DM-EUR exchange rate are similar. Positive news about German output tends to appreciate the euro (or deutschemark), while positive news about U.S. output tends to depreciate it. Although the $R^{2}$ of the regression is low, the joint statistical significance of the explanatory variables is still extremely high, with a $p$-value less than $10^{-5}$. Thus, both of the high-frequency regressions in Table 2 provide a great deal of information with which to estimate and identify time-variation in the sensitivity of exchange rates to news.

Figure 5 plots the estimated time-varying sensitivity coefficients $\delta^{\tau}$ for rolling regression (11) applied to the USD/GBP and USD/DM-EUR exchange rates. The formatting of the two panels is analogous to that in Figures 3 and 4 . The USD/GBP exchange rate sensitivity is close to zero in 2002, and unusually responsive to news in 2005, but otherwise behaves quite normally 

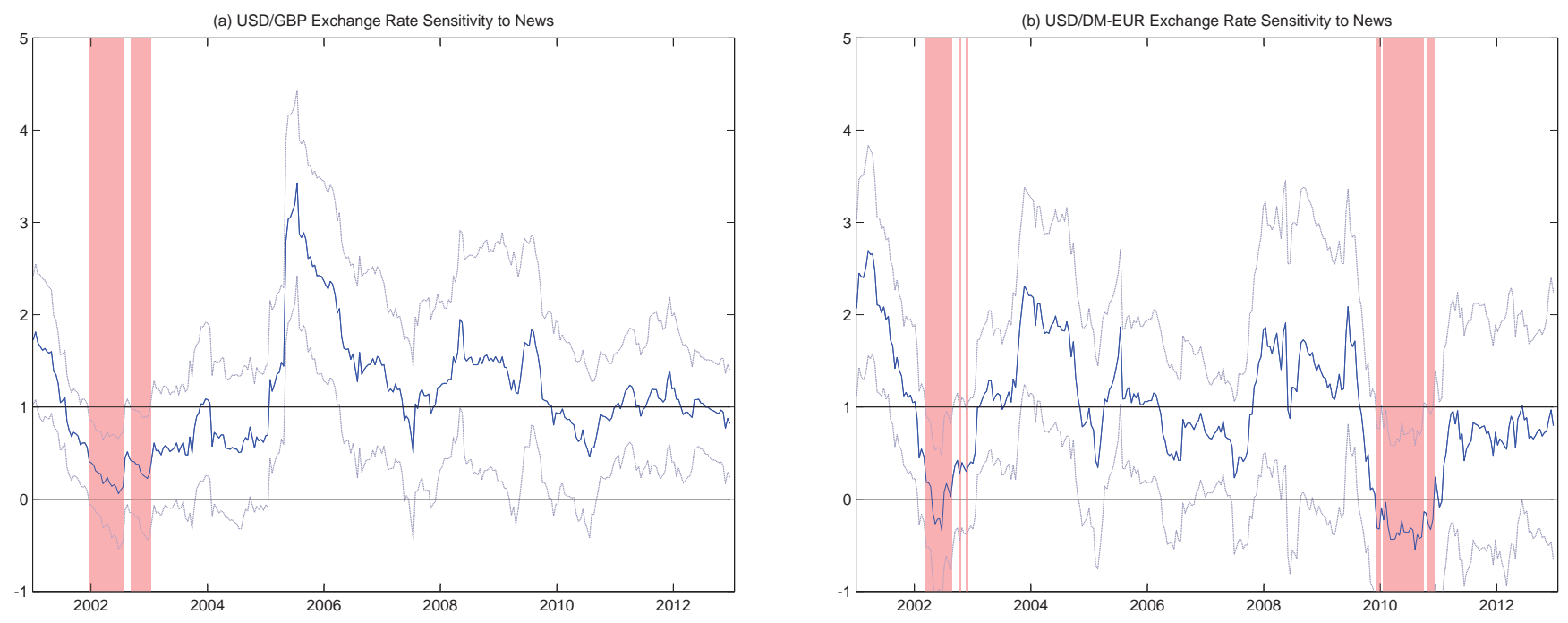

Figure 5. Time-varying sensitivity coefficients $\delta^{\tau}$ from regression (11) for (a) USD/GBP and (b) USD/DM-EUR exchange rates. See notes to Figure 3, Table 4, and text for details.

throughout our sample. In particular, the estimated sensitivity coefficients $\delta^{\tau}$ are very close to unity throughout the 2008-12 period. This suggests that the zero lower bound on nominal interest rates did not significantly constrain the behavior of the pound despite being a significant constraint on short-term interest rates in both the U.S. and U.K.

While this finding might seem surprising, it is exactly what our stylized model in Section 2 predicts. In particular, the level of the exchange rate is determined not just by the current shortterm interest rate differential between the two countries, but by the present value of the entire path of expected future short-term interest rate differentials. Even if short-term rates today are constrained by the zero lower bound, the exchange rate should be largely unaffected if future shortterm interest rates in the two countries are unconstrained. In this respect, the exchange rate is more closely related to long-term bond yields than to short-term interest rates. Our findings for the exchange rate are also corroborated by Glick and Leduc (2013), who show that the U.S. dollar has continued to respond to unconventional monetary policy announcements by the Federal Reserve since 2008 by as much as it formerly responded to traditional monetary policy announcements prior to 2008.

The results for the USD/DM-EUR exchange rate in the second panel of Figure 5 are very similar, except for 2010, when the euro stops responding to news for several months. This is surprising, because longer-term German bunds were no more affected by the zero bound in 2010 than were U.K. gilts. Moreover, by early 2011 the sensitivity of the USD/DM-EUR exchange rate 
returned to normal and remained there through the end of our sample, despite the zero bound becoming a greater constraint on U.S. yields in late 2011 and German yields in late 2012. All of these observations suggest that the brief period of euro insensitivity to news in 2010 was not due to the zero lower bound. Moreover, like the pound, the euro appears to have been essentially unconstrained by the zero bound (or other factors) in 2008-12, with the exception of 2010 for the euro. Thus, we conclude that exchange rates were essentially unconstrained by the zero bound over our sample.

\section{Discussion}

In this section, we explore the broader implications of our empirical results and perform several extensions and robustness checks. First, we investigate additional potential explanations for reduced bond yield or exchange rate sensitivity to news beyond the zero lower bound constraint. Second, we compare our estimates of bond yield and exchange rate sensitivity to private-sector expectations of the future path of monetary policy in the U.K. and Germany. Third, we explore the relationship between our results for U.K. gilt yield sensitivity and the Bank of England's purchases of long-term gilts. Fourth and finally, we discuss the implications of our findings for the fiscal multiplier.

\subsection{Other Causes of Reduced Bond Yield Sensitivity to News}

A striking feature of Figure 3 is the period from 2005-06 when many U.K. gilt yields stopped responding to news despite being far above the zero bound (compare to Figure 2). This finding suggests that factors other than the zero bound could significantly attenuate the sensitivity of bond yields at times. In this section, we consider alternative factors that could be a constraint on yields or otherwise reduce their sensitivity to news. However, we emphasize that just because these other factors may have been operational in the U.K. in 2005-06 does not imply that our empirical methods are flawed. If a bond yield becomes substantially constrained by the zero bound for some period of time, it will stop responding to news and be picked up by our test. The fact that our test seems to have yielded a "false positive" (or Type I error) in this case just means that - as with any econometric test-we must inspect the results carefully and not leap to conclusions. 
Swanson and Williams (2013) note two reasons (other than the zero bound) why interest rate sensitivity to news might vary over time: the level of yields, and the degree of interest rate uncertainty. It has long been known that interest rate volatility-and thus, presumably, interest rate sensitivity to news - declines along with the overall level of yields (e.g., Chan et al., 1992). When interest rates are low, they have less "room to run" and tend to be less volatile. However, looking at the U.K. in 2005-06, gilt yields were at a level of about 4 to 5 percent, not very different from their average over our whole sample. Thus, the level of gilt yields alone seems unlikely to explain the low sensitivity of gilts to news in 2005-06, although it could be a potential factor near the end of our sample when U.K. yields reached historic lows.

Changes in financial market uncertainty about future short-term interest rates could also be an important determinant of bond yield sensitivity to news. Suppose that financial markets use a Kalman filter or Bayesian updating to update their expectations about the path of future shortterm interest rates. Then the financial market sensitivity on day $t$ to a macroeconomic data release depends on the variance of the surprise component of that data release and the day $t-1$ prior variance of the variable being forecast - in this case, the future short-term interest rate. If the market's prior variance is very small, then market participants have a great deal of confidence in their expectation of the future short-term interest rate and will respond relatively little to any data release on date $t$. On the other hand, if the market's date $t-1$ prior variance is very large, then markets will respond much more strongly to any news on date $t$. This effect could help to explain why our estimates of $\delta^{\tau}$ in Figures 3 and 4 are sometimes significantly higher than normal as well as lower than normal; for example, 1- through 5-year German bunds' sensitivity to news triples during the early stages of the financial crisis in 2008, while U.K. gilts double in sensitivity (and U.S. yields' sensitivity increases about 2.5 times, as shown by Swanson and Williams (2013)). And in fact, future short-term interest rate uncertainty was much higher than normal during this period, as can be seen in Figure 6 for the U.K., and in Swanson and Williams' (2013) Figure 9 for the U.S.

Figure 6 plots uncertainty about short-term interest rates derived from options on short sterling (Libor) interest rate futures with twelve months to expiration. ${ }^{22}$ The Bank of England provides

\footnotetext{
${ }^{22}$ The short sterling futures contract trades on the London International Financial Futures and Options Exchange (LIFFE) and is the most liquid sterling-denominated futures contract in the world. It settles based on the spot 3-month Libor rate at expiration. See the Bank of England's and LIFFE's web sites for additional information.
} 


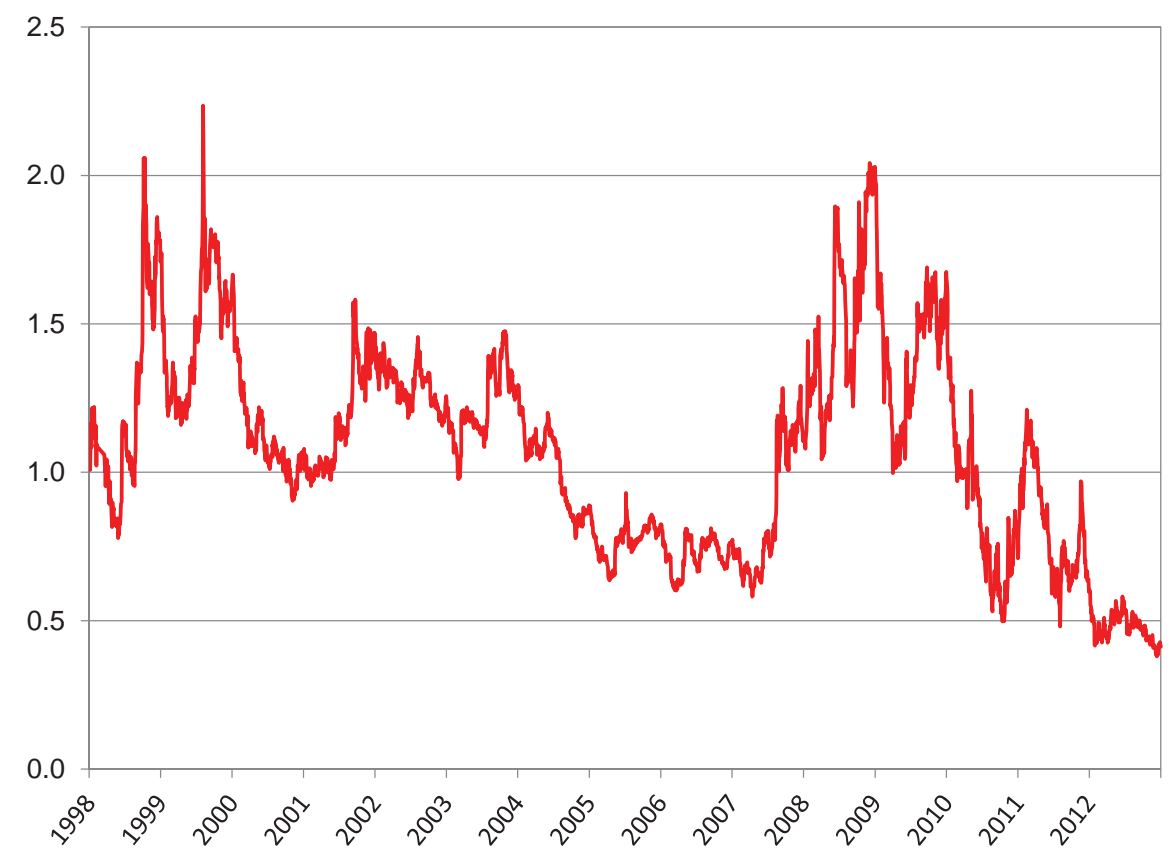

Figure 6. Financial market uncertainty about the path of future short-term U.K. interest rates, as measured by the difference between the $75^{\text {th }}$ and $25^{\text {th }}$ percentiles of the implied distribution of one-year-ahead U.K. sterling Libor in percentage points, derived from options.

daily estimates of the market-implied risk-neutral probability density functions from these options data going back to January 1998, and we plot the difference between the $75^{\text {th }}$ and $25^{\text {th }}$ percentiles of this distribution in Figure 6. (Swanson and Williams, 2013, compute a similar measure for the U.S. using options on eurodollar futures.) The one-year-ahead interquartile range averages about 100 bp between 1998 and 2012, but is much higher during the financial crisis, rising to about 200 $\mathrm{bp}$, and is much lower in 2005-06, about 60-70 bp, and in 2012, about 40-50 bp.

The broad patterns in Figure 6 thus suggest that times of high (resp. low) interest rate uncertainty are also times of high (resp. low) interest rate sensitivity to news. In Table 5, we investigate the importance of this effect by regressing our estimated values of $\delta^{\tau}$ for the 6 -month, 2-year, and 10-year U.K. gilt yields on the interquartile range from Figure 6. These regressions begin in 1998 due to a lack of data on U.K. interest rate uncertainty prior to 1998. At all three maturities, the results in the first column of Table 5 show that the sensitivity of yields to news is very strongly related to short-term interest rate uncertainty, with $t$-statistics over 6.5. The size of the coefficients implies that a 1 percentage point increase in the interquartile range is associated with an increase in gilt yield sensitivity to news of about 0.5 at the 2-year maturity. 
Regressions of U.K. Gilt Yield Sensitivity $\delta^{\tau}$ on Explanatory Variables

(A) 6-month Gilt Yield Sensitivity $\delta^{\tau}$

\begin{tabular}{lcccccc} 
constant & .003 & $(0.07)$ & .005 & $(0.29)$ & -.320 & $(-6.23)$ \\
UK interest rate uncertainty & .572 & $(8.28)$ & & & .355 & $(6.79)$ \\
$\begin{array}{l}\text { 6-month gilt yield level } \\
\text { time trend }\end{array}$ & & & .166 & $(22.97)$ & .151 & $(18.83)$ \\
$R^{2}$ & \multicolumn{2}{c}{.16} & & & & \\
\end{tabular}

(B) 2-year Gilt Yield Sensitivity $\delta^{\tau}$

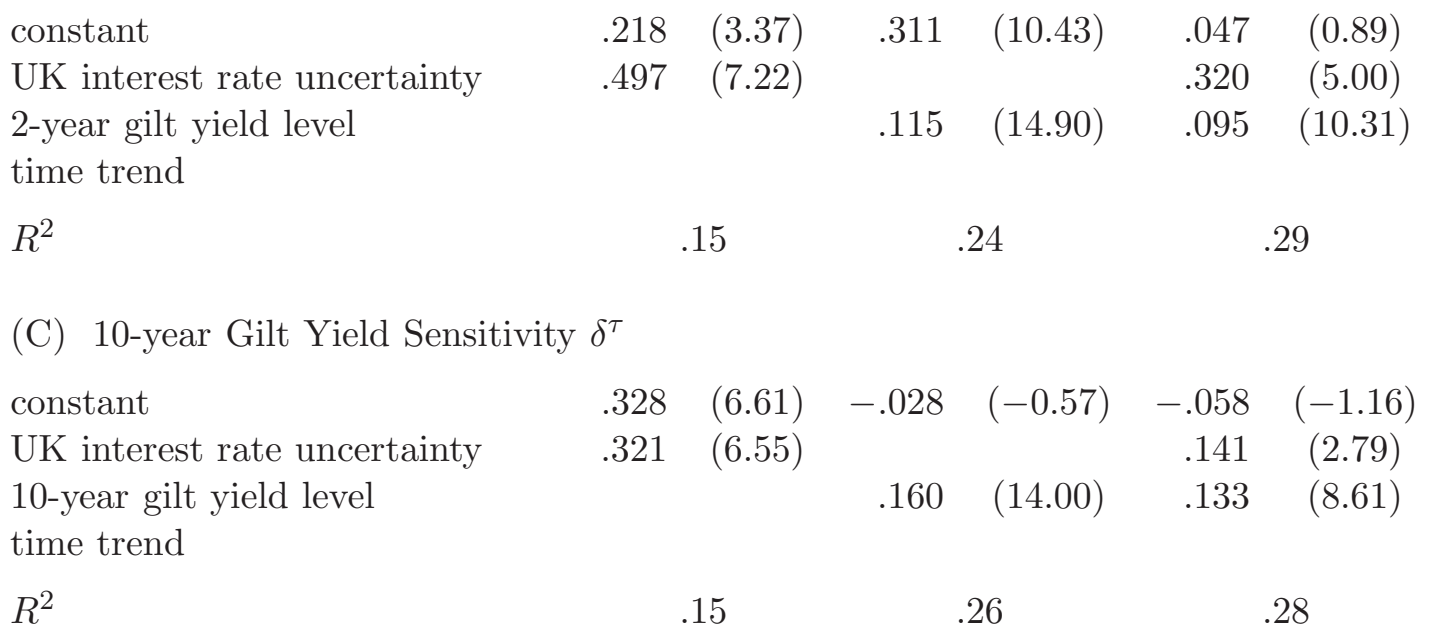

Table 5. Coefficient estimates and $R^{2}$ from ordinary least squares regression of U.K. gilt yield sensitivity $\delta^{\tau}$ on monetary policy uncertainty and interest rate levels at daily frequency from Jan. 1998 to Dec. 2012. U.K. interest rate uncertainty is the interquartile range from Figure 6, in percentage points. Heteroskedasticity-consistent $t$-statistics in parentheses. See text for details.

To check whether the level of yields is also important, the second column of Table 5 regresses the estimated $\delta^{\tau}$ for each yield on the level of that yield. At each maturity, the sensitivity to news is very strongly correlated with the level of yields, with $t$-statistics of at least 14 . A onepercentage-point decline in the level of yields is associated with a fall in $\delta^{\tau}$ of about 0.12 for the 2-year maturity. The third column of Table 5 includes both interest rate uncertainty and the level of yields, and both remain highly statistically significant, albeit with slightly smaller coefficients. ${ }^{23}$

Figure 7 plots the fitted values from these regressions for the 6-month and 2-year U.K. gilt

\footnotetext{
${ }^{23}$ We also experimented with including a time trend in this regression, since there has been a downward trend in monetary policy uncertainty in the U.S. (Swanson, 2006) and perhaps also in the U.K. (Figure 6). A downward trend in uncertainty might be expected to have a different effect on the yield curve's sensitivity to news than variations in uncertainty due to the business cycle or other factors. However, the regression coefficient on the trend was always small and statistically insignificant, and the other coefficients remained very similar to those in the third column.
} 

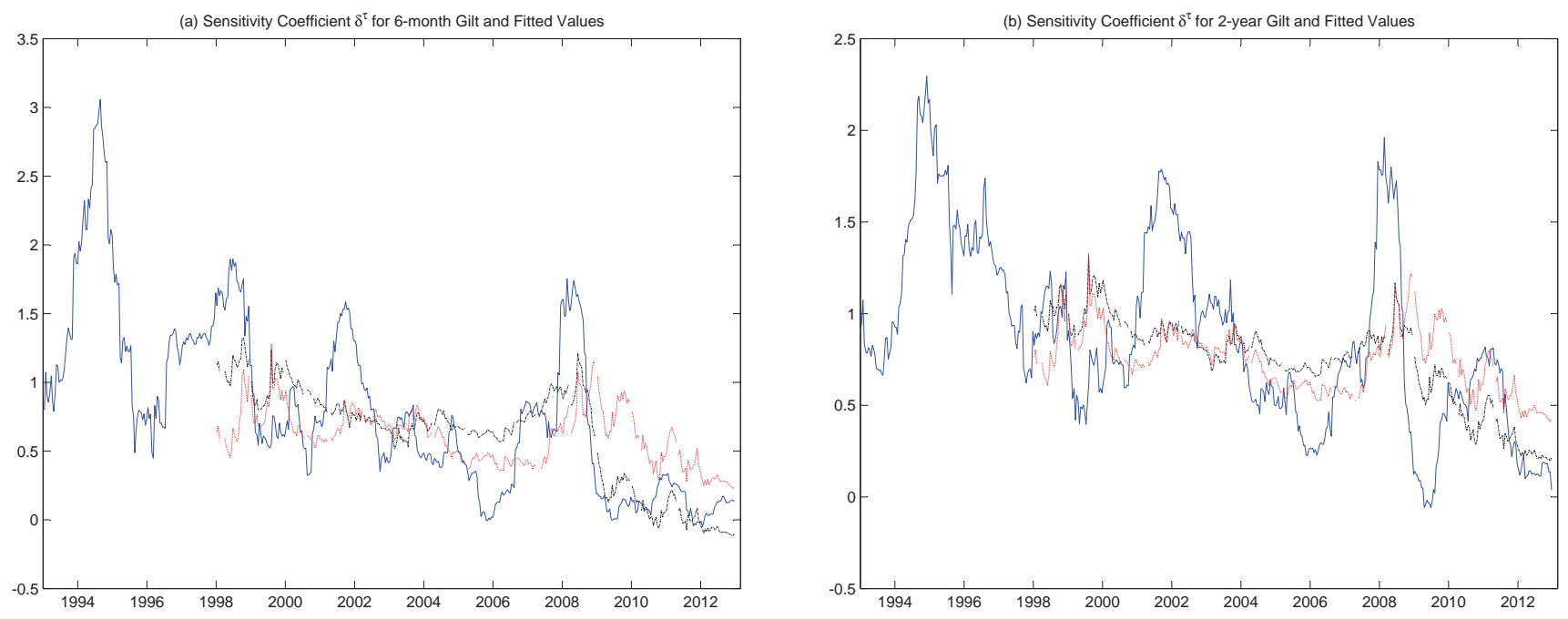

Figure 7. Solid blue line in each panel depicts time-varying sensitivity coefficient $\delta^{\tau}$ from regression (11) for the (a) 6-month and (b) 2-year U.K. gilt yields; dotted red line in each panel plots fitted values from column (1) of Table 5; dash-dotted black line plots fitted values from column (3) of Table 5. See text for details.

yields. In each panel of the figure, the solid blue line depicts the sensitivity coefficient $\delta^{\tau}$ from Figure 3, the dashed red line plots the fitted values from the regression in the first column of Table 5, and the dash-dotted black line plots the fitted values from the regression in the third column of that table.

The low level of gilt yield sensitivity in 2005-06 is matched fairly well by the dashed red lines in Figure 7, suggesting that the low level of monetary policy uncertainty during that period was an important factor in the low sensitivity of gilts to news. Similarly, the historic decline in interest rate uncertainty in 2009-12 can explain part of the large fall in sensitivity at the end of our sample. The dash-dotted black lines in Figure 7, which include the level of yields as well as interest rate uncertainty as explanatory variables, fit the blue lines even more closely in 2009-12, at the cost of losing fit in 2005-06.

Although the historically low level of gilt yields and monetary policy uncertainty in 2009-12 can explain the entire decline in gilt yield sensitivity at the end of Figure 7, that does not imply that the zero lower bound was unimportant. Indeed, the main reason monetary policy uncertainty fell to such low levels at the end of our sample is precisely because of the zero lower bound! That is, there is very little uncertainty about what U.K. short-term interest rates will be in 12 months because those interest rates essentially cannot fall any lower, nor will they rise unless the U.K. 
economy becomes much stronger than it currently is. Thus, even if we attribute all of the decline in gilt yield sensitivity in 2009-12 to the explanatory variables in Figure 7, the zero lower bound can still be regarded as the fundamental driving force behind that decline.

In contrast to U.K. gilts, German bunds do not display a reduced sensitivity to news throughout much of our sample, until late 2012. Thus, there is less of a decline in bund yield sensitivity to explain with other factors. We also do not have a measure of monetary policy uncertainty available to us for Germany, so we cannot perform an analysis along the lines of Table 5. However, monetary policy uncertainty in Germany was almost certainly very high in late 2007 and 2008, as the financial crisis was unfolding, which would help explain the very high level of bund yield sensitivity to news during that period. From 2003 through the end of 2005, the ECB's monetary policy rate was also unusually stable (see Figure 2), suggesting that monetary policy uncertainty was unusually low toward the end of that period, consistent with the low level of bund sensitivity at that time. Thus, the results for Germany are qualitatively consistent with those for the U.K. in Table 5.

\subsection{Gilt and Bund Yield Sensitivity to News in 2009-12}

Given the low level of gilt and bund yields in 2009-12 (see Figure 2), it is perhaps surprising that those yields were not more constrained by the zero lower bound during the financial crisis and its aftermath. Only beginning in late 2011 did the sensitivity of 1- to 3-year U.K. gilts fall close to zero, and German bunds did not experience a decline in sensitivity until mid-2012.

The fact that U.K. and German bond yields were greater than zero over part of this period does not necessarily imply those yields were unconstrained. For example, $50 \mathrm{bp}$ appears to have been an effective lower bound on the Bank of England's monetary policy rate, as discussed in the Introduction. ${ }^{24}$ If financial markets expected Bank Rate to remain at 50 bp for a very long time because of an effective lower bound, then our regressions should pick up that period as one in which gilt yields stopped responding to news, particularly at the shorter end of the yield curve. (And our regressions do pick up the period in 2009 and from late 2011 onward as being such periods.) The

\footnotetext{
${ }^{24}$ In particular, after lowering Bank Rate to 50 bp on March 5, 2009, the Bank of England began conducting purchases of longer-term gilts and other assets on a similar scale to the U.S. Federal Reserve, which was operating with the federal funds rate target at about zero. Bernanke and Reinhart (2004) discuss several reasons why institutional constraints in a country's financial markets might prevent its central bank from lowering the monetary policy rate all the way down to zero.
} 


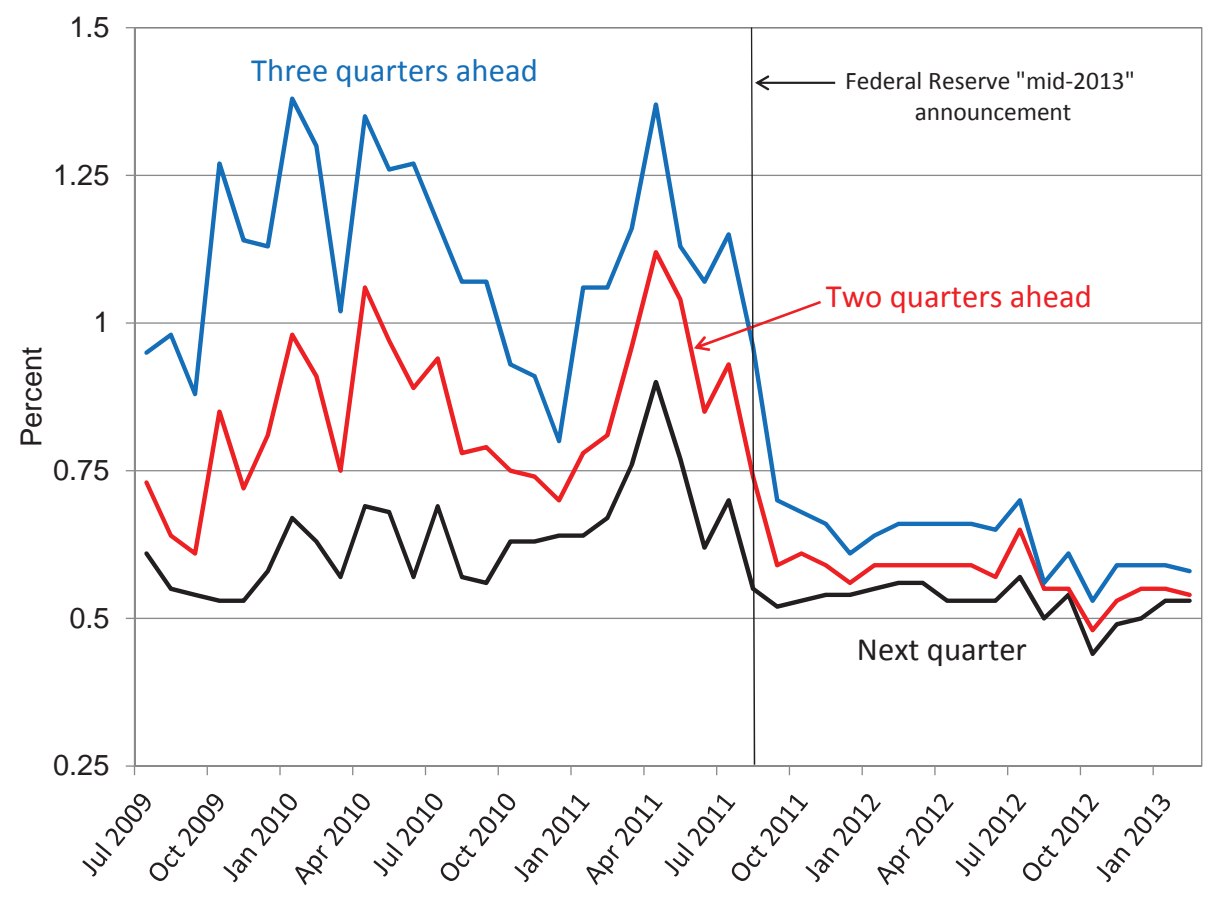

Figure 8. Professional forecasters' expectation of the end-of-quarter U.K. Bank Rate at the end of quarters $t+1, t+2$, and $t+3$, where the current quarter is $t$, as measured by the monthly Consensus Economics survey from July 2009 through February 2013. There is a sharp drop in these expectations around the time of the U.S. Federal Reserve's announcement of Aug. 9, 2011. See text for details.

fact that 2010-11 does not show up as such a period for 1- to 3-year gilts thus represents something of a puzzle.

Figure 8 sheds some light on this puzzle by graphing financial markets' expectation of the end-of-quarter Bank Rate one, two, and three quarters ahead - that is, at the end of quarters $t+1$, $t+2$, and $t+3$, where the current quarter is $t$-as measured by the mean of the monthly Consensus Economics survey of professional forecasters from July 2009 through February $2013 .^{25}$ According to our illustrative model in Section 2, the length of time that the monetary policy rate is expected to be at the lower bound is closely related to the sensitivity of bond yields to news. If Bank Rate is expected to remain at $50 \mathrm{bp}$ for just one quarter, then gilts should be essentially unconstrained by the lower bound, whereas if Bank Rate is expected to be at 50 bp for several years, then even 5-year gilt yields might be substantially constrained.

From 2009 through mid-2011, professional forecasters generally expected the Bank of Eng-

\footnotetext{
${ }^{25}$ Consensus Economics began surveying professionals forecasters about their expectations for Bank Rate beginning in July 2009, so we cannot extend the figure further backward in time.
} 
land to raise Bank Rate by 50 to $75 \mathrm{bp}$ within the next three to four quarters. Moreover, these expectations fluctuated substantially over this period, as the economic and monetary policy outlook in the U.K. varied. Only beginning in late 2011 do we see these expectations drop to a level close to the effective lower bound of $50 \mathrm{bp}$ and remain there. These survey data thus corroborate our findings for 1- to 3-year gilt yields over the same period: When financial markets expected Bank Rate to rise substantially over the next 3-4 quarters, 1- to 3-year gilt yields responded to macroeconomic announcements by almost as much as in normal times. But when financial market expectations of Bank Rate over the next 3-4 quarters fell to the effective lower bound in late 2011, intermediate-maturity gilts stopped responding to news almost completely.

Indeed, the sharp drop in these expectations around September 2011 is striking and calls for an explanation. There are two developments around this time that are likely to have played an important role. First, the U.K. economy weakened in the second half of 2011, with GDP growth turning slightly negative in 2011Q4, 2012Q1, and 2012Q2. To the extent that the weakening economy was foreseen as early as September 2011, this would explain the sharp fall in financial market expectations for the monetary policy rate as well. Additional support for this explanation is provided by the sharp fall in monetary policy expectations near the end of 2010; around this time, U.K. GDP growth turned from slightly positive in 2010Q3 to slightly negative in 2010Q4, before turning positive again in the first quarter of 2011. Nevertheless, one might wonder why the decline in monetary policy expectations in Figure 8 is so sharp right around September 2011, rather than being more gradual.

The second development around this time is the U.S. Federal Reserve's announcement on August 9, 2011, that it expected to keep the federal funds rate at its floor of essentially zero "through at least mid-2013." As shown by Swanson and Williams (2013), this announcement led to a sudden, dramatic fall in financial market expectations of the future path of the federal funds rate. Even though the Fed's announcement had no direct implications for the conduct of monetary policy in the U.K., the timing of the drop in expectations in Figure 8 suggests that the Fed's announcement may have spilled over to financial market expectations about the likely future path of monetary policy in the U.K. as well. ${ }^{26}$ The Fed's announcement may also have carried additional

\footnotetext{
${ }^{26}$ We do not take a stand on why this might be so, but note that there could be several reasons. For example, financial market participants may have thought that the Bank of England would be likely to follow the Fed's example
} 


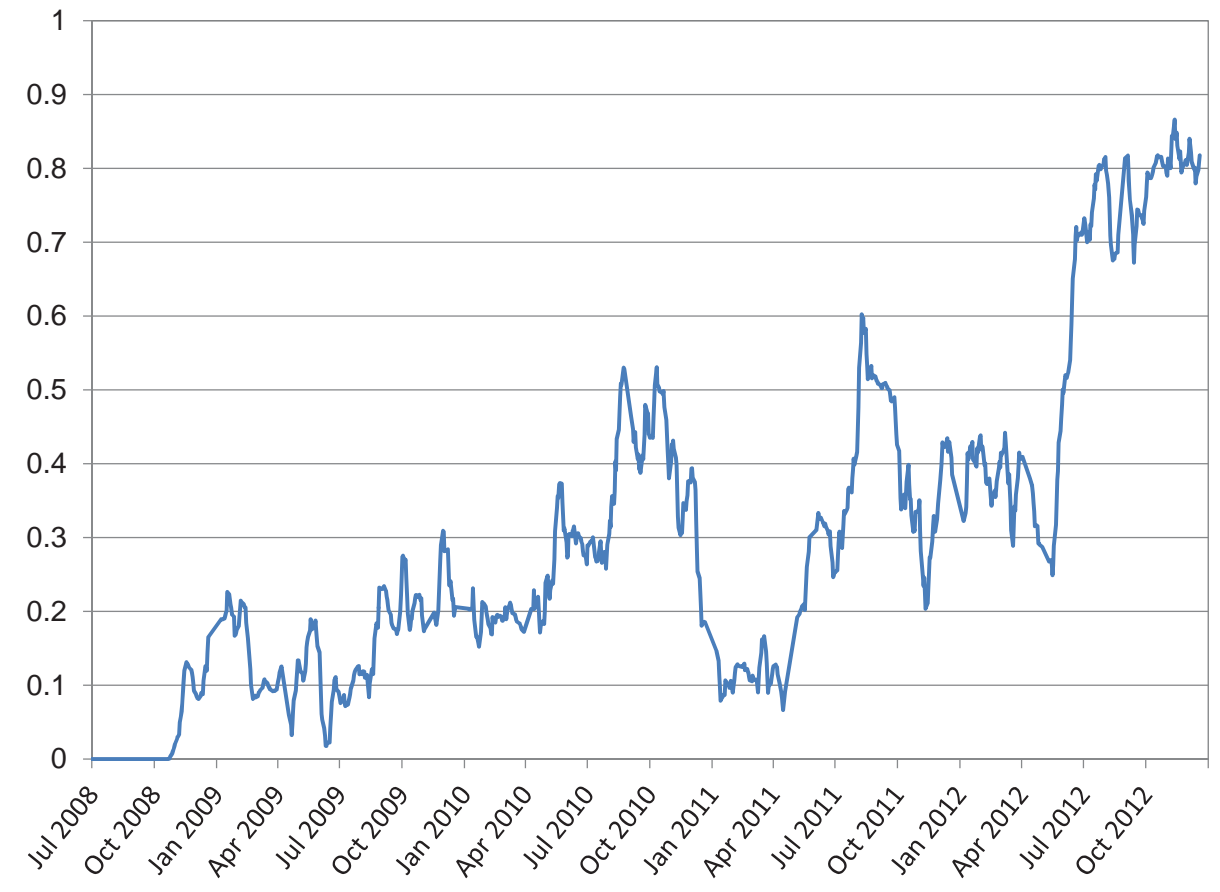

Figure 9. Probability of U.K. sterling Libor rate being less than $75 \mathrm{bp}$ in twelve months' time, estimated from options data. See text for details.

weight in the U.K. when viewed against the backdrop of weakening British GDP at the time.

Figure 9 presents additional data on financial market interest rate expectations from the U.K. options market. On each day from July 2008 through December 2012, Figure 9 plots the probability that the 3-month sterling Libor rate would be less than $75 \mathrm{bp}$ in twelve months' time, using the riskneutral probability density functions for sterling Libor computed by the Bank of England. Early in 2008, the options market assigned essentially zero probability to sterling Libor being below 75 bp one year ahead. But even in 2009 and the first half of 2010 - a period that includes the depths of the recession - this probability remained low, fluctuating between roughly 10 and 20 percent. Market participants apparently expected the Bank of England to raise interest rates within just a few quarters, either because the U.K. economy would bounce back quickly from the recession or because U.K. inflation would rise above the Bank's target. (This finding parallels Swanson and Williams' (2013) findings for the U.S., where financial markets also incorrectly expected interest rates to rise quickly.) This probability rises and falls along with the outlook for the U.K. economy and monetary policy, but only beginning in August 2011, and again in May-June 2012, do we see and issue a similar statement of forward guidance. Alternatively, markets could have taken the Fed's announcement as a signal that the global economic and financial outlook was worse than they had thought. 
the probability rise to a consistently higher level. ${ }^{27}$

Like the Consensus survey data, these results corroborate our findings for intermediatematurity gilt yields in Figure 3 and suggest that financial markets did not expect Bank Rate to remain at its effective lower bound for more than a few quarters, until late 2011. This can explain why the sensitivity of intermediate-maturity gilt yields to news is so high throughout 2010 and 2011, despite the severity of the recession.

Our discussion up to this point has focused on the U.K., but our results for Germany in Figure 4 provide an interesting contrast. For Germany, it's not clear that financial markets viewed the level of 1 percent as an effective floor on the ECB's monetary policy rate in 2009-12. In fact, the ECB lowered the main refinancing rate to 0.75 percent on July 11, 2012, and lowered it further to 0.5 percent on May 8, 2013. Thus, ex post, 1 percent was not a floor on the ECB's policy rate. Moreover, the ECB actually raised the refinancing rate twice between 2009 and 2012, to 1.25 percent on April 13, 2011, and 1.5 percent on July 13, 2011. The fact that the ECB was raising rates during this period suggests that its desired monetary policy rate was not much constrained by a floor of 1 percent earlier in 2011, and perhaps not even in 2009-10.

Our results for Germany in Figure 4 are consistent with this view. Between 2008 and mid2012, 1- and 2-year bund yields responded to macroeconomic announcements by essentially as much as in normal times. Only beginning in the second half of 2012-around the time the ECB cut the main refinancing rate to 0.75 percent - do we see 1- and 2-year bunds begin to behave in a more constrained manner.

\subsection{The Bank of England's Purchases of Longer-Term Gilts}

Between 2009 and the end of our sample, the Bank of England undertook a series of large-scale purchases of longer-term gilts on the open market, amounting to about $£ 375$ billion in total. Although standard representative-agent asset pricing models do not allow the quantity of a security in the market to affect its price, Vayanos and Vila (2009) provide a modern, arbitrage-free foundation for the earlier "portfolio balance" and "preferred habitat" models of Tobin (1958) and Modigliani and

\footnotetext{
${ }^{27}$ The period May-June 2012 was dominated by financial market concernes about the European sovereign debt crisis spilling over from Greece to larger eurozone countries such as Spain and Italy. Thus, the sharp increase in the length of time the zero bound was expected to bind in the U.K. appears to be related to the worsening economic outlook in Europe.
} 
Sutch (1966). ${ }^{28}$ Intuitively, if investors are heterogeneous and differ in their preferences for various bond maturities, and if arbitrage across maturities is limited, then the supply of longer-term bonds in the market can have important effects on longer-term bond yields. Thus, even if a central bank's monetary policy rate is constrained by the zero lower bound, it may nevertheless be able to affect longer-term yields through large-scale purchases of longer-term bonds (as well as through forward guidance regarding the future path of the monetary policy rate).

For example, on March 5, 2009, the Bank of England lowered Bank Rate to 0.5 percent and, because it viewed this as an effective lower bound on the monetary policy rate, announced it would purchase $£ 75$ billion of longer-term gilts on the open market over the next three months. While Bank Rate has remained at this floor, the Bank of England has conducted several more rounds of large-scale gilt purchases, amounting to about 29 percent of total gilts in the hands of the private sector, and an even greater percentage of longer-term gilts (Joyce et al., 2011). ${ }^{29}$

Empirically, several studies suggest that such large-scale purchases of government bonds affect the yields of those securities. Joyce et al. (2011) and Christensen and Rudebusch (2012) study the effects of the Bank of England's asset purchases in particular, while Bernanke et al. (2004), Krishnamurthy and Vissing-Jorgensen (2011, 2012), Gagnon et al. (2011), and Swanson (2011) study the effects of changes in the supply of U.S. Treasuries on Treasury yields over a variety of different episodes using a variety of methods.

These empirical studies suggest that the Bank of England's gilt purchases had a significant effect on longer-term gilt yields. Moreover, they suggest that changes in financial markets' expectations of future gilt purchases by the Bank of England would affect yields. That is, as the U.K. economic outlook varies over time, financial market expectations regarding the size of Bank asset purchases tend to vary, and we would expect to see longer-term gilt yields vary along with these changes in expectations; thus, we would expect to see these yields continue to respond to

\footnotetext{
${ }^{28}$ See also Hamilton and $\mathrm{Wu}(2012)$, who relate the Vayanos-Vila model to a standard arbitrage-free affine term structure model to estimate quantity effects.

${ }^{29}$ On May 7, 2009, the Bank announced it would expand the size of this program by an additional £50-125 billion, and on November 5, 2009, the program was expanded again, to a total size of $£ 200$ billion. The Bank's holdings remained at this level until October 2011, at which point they began to be increased again in response to a weakening economic outlook for the U.K. On Oct. 6, 2011, the Bank announced it would increase the size of its asset purchase program to $£ 275$ billion; on Feb. 9, 2012, the program was increased again to $£ 325$ billion; and on July 5, 2012, the program was increased to $£ 375$ billion. As of this writing, the size of the Bank of England's gilt holdings remains at about $£ 375$ billion. Additional details of the Bank's purchases are provided in Joyce et al. (2011) and on the Bank of England's web site.
} 
major macroeconomic announcements. Even when Bank Rate itself was constrained by an effective lower bound of 0.5 percent, variations in the size of the Bank of England's asset purchase program represent an additional channel - along with Bank Rate expectations - through which longer-term gilt yields can continue to respond to news.

In the bottom panels of Figure 3, then, it is perhaps not surprising that 5- and 10-year gilts were not significantly attenuated in their sensitivity to news. Even though Bank Rate was at its effective lower bound throughout this period, and 2- and 3-year gilts behaved in a constrained manner, gilts at the 5- and 10-year maturities can continue to respond to news in much the same way as in normal times.

\subsection{Implications for the Fiscal Multiplier}

As discussed in Swanson and Williams (2013), our empirical results have important implications for the growing literature on the fiscal multiplier at the zero lower bound (e.g., Christiano et al. 2011, Woodford 2011). ${ }^{30}$ An important finding of that literature is that the fiscal multiplier is larger the greater the fraction of the change in government spending that is expected to take place while the monetary policy rate is at zero. ${ }^{31}$ Put differently, for a given path of fiscal stimulus, the multiplier is larger the longer the zero lower bound is expected to constrain the monetary policy rate.

Figure 10 illustrates two possible scenarios for the expected path of short-term interest rates. In scenario A (the red line), the short-term rate is expected to lift off from the zero bound relatively quickly, at time $t_{A}$. In scenario $\mathrm{B}$ (the blue line), the short-term rate is expected to lift off later, at $t_{B}>t_{A}$. According to the analysis in Woodford (2011) and Christiano et al. (2011, henceforth $\mathrm{CER}$ ), for a given increase or decrease in the expected path of government purchases between time 0 and $t_{B}$, the fiscal multiplier is larger in scenario $\mathrm{B}$ than in scenario $\mathrm{A}$, for two reasons. First, in scenario B a greater fraction of the change in government purchases takes place while the

\footnotetext{
${ }^{30}$ See also Eggertsson (2009), Erceg and Lindé (2010), Eggertsson and Krugman (2012), and DeLong and Summers (2012).

${ }^{31}$ For example, "Our basic result is that the multipliers are higher the larger the percentage of the spending that comes on line when the nominal interest rate is zero" (Christiano et al. 2011, p. 112). "Hence, while there is a positive effect on output during the crisis of increased government purchases at date $t<T$, an anticipation of increased government purchases at dates $t \geq T$ has a negative effect on output prior to date T" (Woodford 2011, p. 22). "A key lesson from this analysis is that... it is critical that the spending come on line when the economy is actually in the zero bound. Spending that occurs after that yields very little bang for the buck and actually dulls the impact of the spending that comes on line when the zero bound binds" (Christiano et al. 2011, p. 112).
} 


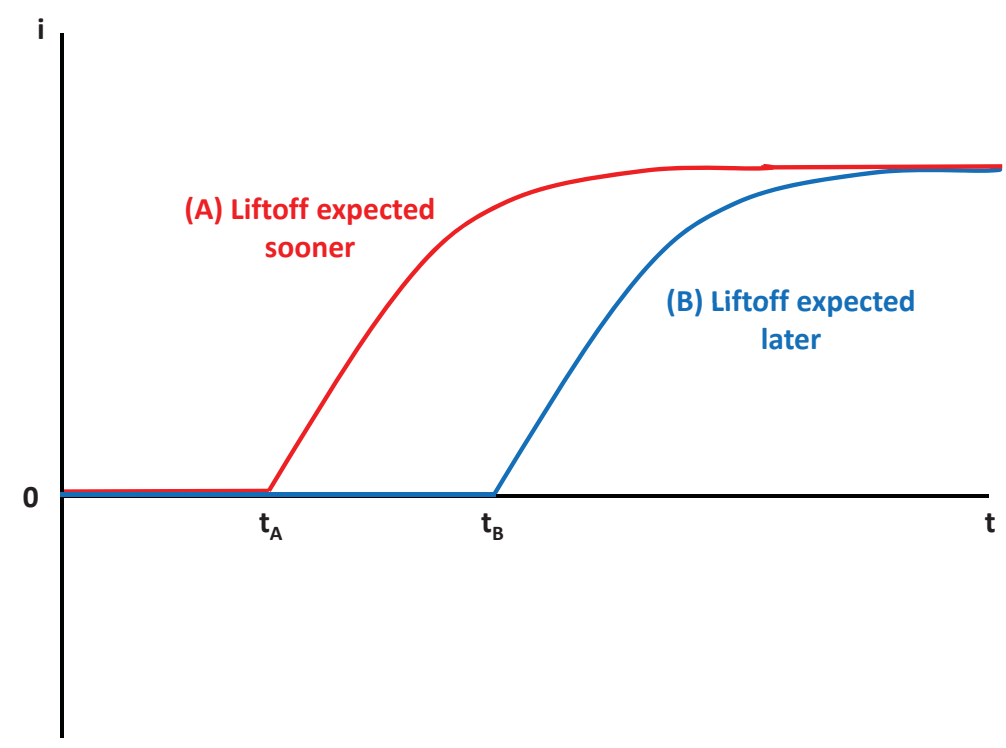

Figure 10. Two scenarios for the length of time the short-term interest rate is expected to remain at the zero lower bound: in scenario A (red line), liftoff from the zero bound is expected sooner; in scenario B (blue line), later. For a given increase in the expected path of government purchases between time 0 and $t_{B}$, the fiscal multiplier is larger in scenario B than in A (Woodford 2011, Christiano et al. 2011). Our empirical results shed light on the relative plausibility of scenarios A and B at various times in the U.K. and Germany. See text for details.

short-term interest rate is zero, which increases the fiscal multiplier. Second, in scenario B the zero lower bound is expected to bind for a longer period of time, which by itself also increases the fiscal multiplier, as discussed by those authors.

Our empirical results shed light on the relative plausibility of different scenarios such as A and B in Figure 10 at various times in the U.K. and Germany. For example, in 2010-11, our findings suggest that financial markets expected the U.K. monetary policy rate to lift off from its effective lower bound in just a few quarters, a relatively short period of time reminiscent of scenario A. In contrast, in 2009 and again from late 2011 through the end of our sample in 2012, our findings suggest that financial markets expected Bank Rate to remain at its lower bound for a longer period of time, similar to scenario B. According to the analysis in CER, when the zero bound is expected to constrain the monetary policy rate for a relatively short period of time - 4 quarters or less - the fiscal multiplier is essentially no different from normal. ${ }^{32}$ Only when the zero bound is expected to bind for a longer period of time - either 8 or 12 quarters in CER's analysis - do those authors find the fiscal multiplier to be substantially greater than normal.

Based on the results in CER and our own estimates of the length of time markets expected the

\footnotetext{
${ }^{32}$ See Christiano et al. (2011), footnote 12 .
} 
zero bound to constrain short-term interest rates in the U.K. and Germany, we conclude that the fiscal multiplier in the U.K. was likely close to normal from 2010 to late 2011. Only in 2009, and again from late 2011 through the end of our sample in 2012, would we expect the fiscal multiplier to approach the larger values estimated by CER. ${ }^{33}$ For Germany, our estimates imply that the fiscal multiplier was probably close to normal from 2008 to mid-2012. Only beginning in the second half of 2012, when 2-year bund yields stopped responding significantly to news, would we expect the fiscal multiplier to take on the larger values estimated by CER.

More generally, Figure 10 suggests that the sensitivity of intermediate-maturity bond yields to economic news is a good indicator of the relative size of the fiscal multiplier. In scenario B, when the zero bound is expected to constrain short-term interest rates for a longer period of time, intermediate-maturity bond yields are less sensitive to news than in scenario A. Thus, as a general rule, periods when the fiscal multiplier is larger are also periods when intermediate-maturity bond yields are less sensitive to economic news, consistent with the standard IS-LM intuition of a smaller degree of crowding out.

\section{Conclusions}

In this paper, we applied the methods of Swanson and Williams (2013) to measure whether and to what extent exchange rates and interest rates in the U.K. and Germany have been affected by the zero lower bound on nominal interest rates. Our estimates provide both a quantitative measure of the severity of the effects of the lower bound on each bond yield (or exchange rate) and a statistical test for the periods during which that interest or exchange rate was affected.

We find that both the USD/GBP and USD/DM-EUR exchange rates were essentially unaffected by the zero lower bound throughout our sample. Even though short-term interest rates in the U.S. and U.K. were substantially constrained from 2009-12, the current level of the exchange rate is related in theory to the present value of future interest rate differentials between the two countries. As a result, the exchange rate behaves more like a long-term than a short-term interest

\footnotetext{
${ }^{33}$ It is interesting that financial markets' expectation of a quick liftoff from the lower bound in 2010-11 turned out to be incorrect ex post. Nevertheless, as is clear from Woodford's (2011) analysis, it is the private sector's expectations at time $t$ regarding the future path of short-term interest rates and government spending that is crucial for determining the effect on output at time $t$.
} 
rate differential.

For U.K. gilts, we find that interest rates with a year or more to maturity were surprisingly responsive to news from 2010 through late 2011. Only in 2009, and from late 2011 through the end of our sample in 2012, do we see the sensitivity of intermediate-maturity gilt yields to news fall close to zero. There appear to be two main reasons for the late-2011 decline in sensitivity: First, the U.K. economic outlook began to deteriorate in late 2011, which would have pushed U.K. monetary policy expectations lower; and second, the Federal Reserve's announcement in August 2011 that it expected to keep interest rates unchanged "through at least mid-2013" may have spilled over to affect interest rate expectations in the U.K. as well.

For German bunds, we find that interest rates with a year or more to maturity responded to news about normally until the second half of 2012. At that time, the European Central Bank cut its main refinancing rate below 1 percent for the first time, to 0.75 percent. Prior to that time, interest rates in Germany appear to have been essentially unaffected by the zero lower bound.

Our results have important implications for both monetary and fiscal policy. For monetary policy, our findings imply that policymakers in the U.K. and eurozone had substantial room to affect medium- and longer-term interest rates from 2010 to late 2011 in the U.K., and until at least mid-2012 in Germany. This is true even though the Bank of England's monetary policy rate was at an effective floor of 0.5 percent throughout 2009-12.

For fiscal policy, our empirical findings for the U.K. and Germany, together with the analysis in Christiano et al. (2011), suggest that the fiscal multiplier was probably close to normal in the U.K. from 2010 to mid-2011, and in Germany until at least mid-2012. Only in late 2011 or late 2012, when intermediate-maturity bond yields in these two countries began to show reduced sensitivity to news, would our results suggest that the fiscal multiplier approached the larger values estimated by Christiano et al. (2011) and other authors.

More generally, the methods of Swanson and Williams (2013), which we have used in the present paper, can be extended beyond the U.S., U.K., and Germany to any economy for which sufficiently rich high-frequency data are available. In particular, it would be very interesting to see our methods applied to other countries that have faced the zero lower bound in recent years, such as Japan, Canada, Sweden, and other European countries. 


\section{A Appendix}

\section{A.1 Macroeconomic Data Releases and Survey Forecasts}

As discussed in Section 3.2, we obtained data on major macroeconomic data releases and financial market expectations of those releases from two sources: Bloomberg Financial Services and Money Market Services (MMS). These data are available for purchase from Bloomberg and from Haver Analytics, which bought the rights to the historical MMS data, and continues to conduct the MMS survey.

Both Bloomberg and MMS survey financial market institutions and professional forecasters about their expectations for upcoming major data releases, and we take the median survey response as our measure of the financial market expectation. The MMS survey is conducted weekly, on the Friday before each statistic is released. The Bloomberg survey can be updated at any time by survey participants up until the night before the release. Both Bloomberg and MMS also report the actual value of the data as it was released a few days later, so that it is easy to compute the median survey forecast error as the actual released value of the data less the median survey forecast.

Bloomberg survey data begin around 1996 or 1997 for most major macroeconomic series in the U.S. and elsewhere. Data from MMS go back further, to about 1990 or earlier for most major U.S. macroeconomic announcements, to about 1993 for British announcements, and to about 1995 for German announcements. When the Bloomberg and MMS survey data overlap, they agree very closely, since they are surveying essentially the same set of financial institutions and professional forecasters. In our analysis in this paper, we give priority to the Bloomberg forecast data when it is available, for two reasons: first, the Bloomberg data is in principle a few days "fresher" (although in practice there is no discernible difference between the corresponding MMS and Bloomberg forecasts); and second, because the Bloomberg data are more readily available to us for the past few years.

The nine major U.S. macroeconomic data releases we include in our regressions in this paper are reported in Table A1. Both Bloomberg and MMS provide data for additional U.S. macroeconomic data releases (such as auto sales, new home sales, leading indicators, and several others), but these did not have a statistically significant effect on either U.K. or German yields or exchange 


\begin{tabular}{|c|c|c|c|}
\hline Macroeconomic Series & Units & $\begin{array}{c}\text { Money Market } \\
\text { Services/Bloomberg } \\
\text { Identifiers }\end{array}$ & $\begin{array}{c}\text { Historical } \\
\text { Standard Dev. } \\
\text { of Surprises }\end{array}$ \\
\hline Capacity Utilization & index, out of 100 & $\begin{array}{c}\text { M111CU, } \\
\text { CPTICHNG }\end{array}$ & 0.34 index points \\
\hline $\begin{array}{l}\text { Consumer Price Index } \\
\text { excl. Food \& Energy }\end{array}$ & $\begin{array}{l}\text { pct. change from } \\
\text { previous month }\end{array}$ & $\begin{array}{l}\text { M111CPCM, } \\
\text { CPUPXCHNG }\end{array}$ & 0.09 percentage points \\
\hline Real GDP (advance) & $\begin{array}{l}\text { pct. change from } \\
\text { previous quarter }\end{array}$ & $\begin{array}{l}\text { M111GPAA, } \\
\text { GDAPADVN }\end{array}$ & 0.77 percentage points \\
\hline $\begin{array}{l}\text { Initial Claims for } \\
\text { Unemp. Insurance }\end{array}$ & $\begin{array}{c}\text { thousands of } \\
\text { workers }\end{array}$ & $\begin{array}{l}\text { M111IC, } \\
\text { INJCJC }\end{array}$ & 18.6 thousand workers \\
\hline $\begin{array}{c}\text { ISM/NAPM Survey } \\
\text { of Manufacturers }\end{array}$ & index & $\begin{array}{l}\text { M111PMIF, } \\
\text { NAPMPMI }\end{array}$ & 2.01 index points \\
\hline Nonfarm Payrolls & $\begin{array}{c}\text { change from prev. } \\
\text { month (000s) }\end{array}$ & $\begin{array}{l}\text { M111ED, } \\
\text { NFPTCH }\end{array}$ & 97.9 thousand workers \\
\hline $\begin{array}{l}\text { Producer Price Index } \\
\text { excl. Food \& Energy }\end{array}$ & $\begin{array}{l}\text { pct. change from } \\
\text { previous month }\end{array}$ & $\begin{array}{l}\text { M111PPCM, } \\
\text { PXFECHNG }\end{array}$ & 0.26 percentage points \\
\hline Retail Sales ex. autos & $\begin{array}{l}\text { pct. change from } \\
\text { previous month }\end{array}$ & $\begin{array}{l}\text { M111RSXM, } \\
\text { RSTAXMOM }\end{array}$ & 0.43 percentage points \\
\hline Unemployment Rate & $\begin{array}{l}\text { pct. of } \\
\text { labor force }\end{array}$ & $\begin{array}{l}\text { M111EUR, } \\
\text { USURTOT }\end{array}$ & 0.15 percentage points \\
\hline
\end{tabular}

Table A1. Details of major U.S. macroeconomic announcements included in our regression analysis. Historical standard deviation of surprises is for the period 1990-2012. See text for details.

rates in our regressions, so we dropped those additional series in the interest of parsimony.

The first column of Table A1 reports the series name. In some cases, Bloomberg and MMS may collect data on a few different versions of a given series, such as the percent change from month to month and the percent change over the past 12 months. The second column of Table A1 reports the version of each series used in our analysis; typically this is the month-to-month change if available, since that is the version that is most frequently cited and discussed in the U.S. financial press. The third column of the table reports the MMS and Bloomberg database identifiers for each data series, with the MMS identifier reported first. The final column of the table reports the historical standard deviation of the surprises in the series - that is, the time series standard deviation of the median survey forecast errors for that series - from January 1990 through December 2012.

Table A2 reports the details for the corresponding major U.K. macroeconomic series used in our regressions. In contrast to the U.S., we typically use the percent change from the previous 


\begin{tabular}{cccc} 
Series Name & Units & $\begin{array}{c}\text { Money Market } \\
\text { Services/Bloomberg } \\
\text { Identifiers }\end{array}$ & $\begin{array}{c}\text { Historical } \\
\text { Standard Dev. } \\
\text { of Surprises }\end{array}$ \\
\hline Average Earnings & $\begin{array}{c}\text { pct. change from } \\
\text { previous year }\end{array}$ & M112AEPY & 0.27 percentage points \\
Real GDP (advance) & $\begin{array}{c}\text { pct. change from } \\
\text { previous year }\end{array}$ & $\begin{array}{c}\text { M112GPPY, } \\
\text { UKGRABIY }\end{array}$ & 0.26 percentage points \\
Manufacturing Production & pct. change from & M112MFPY, & 0.75 percentage points \\
previous year & UKMPIYOY & \\
Producer Price Index, & pct. change from & M112PPIY, & 1.29 percentage points \\
Net Input & previous year & UKPPIIY & \\
Retail Sales Volume & pct. change from & M112RSRY, & 0.87 percentage points \\
exc. Autos \& Fuel & previous year & UKRVAYOY & \\
Retail Price Index & pct. change from & M112RPXY, & 0.18 percentage points \\
excl. mortgage interest & previous year & UKRPXYOY & \\
Unemployment Claimant & change from prev. & M112EUD & 14.2 thousand workers \\
Count & month (000s) & &
\end{tabular}

Table A2. Details of major U.K. macroeconomic announcements included in our regression analysis. Historical standard deviation of surprises is for the period 1993-2012. See text for details.

year rather than the month-to-month change for two reasons: first, the change from a year ago is the version that is typically cited and discussed in the U.K. financial press; and second, MMS and Bloomberg data for the month-to-month changes typically do not go back as far in time as the one-year changes and are not covered by as large a set of forecasters. For two of the series used in our analysis - average earnings and the unemployment claimant count - we were unable to obtain survey data from Bloomberg at all, so we purchased the MMS versions of those series up through the end of 2012.

As for the U.S., both MMS and Bloomberg collect data on other major U.K. macroeconomic announcements not listed in Table A2 (for example, the unemployment rate, industrial production, a producer price index for outputs, and several others). We did not include these other series in our analysis because they did not have a statistically significant effect on either U.K. or German interest rates or exchange rates over our sample.

Table A3 reports the details for the corresponding major German macroeconomic series used in our regressions. Like the U.S., but in contrast to the U.K., we typically use the percent change from the previous month for each series, since that is the version of the data which typically had 


\begin{tabular}{|c|c|c|c|}
\hline Series Name & Units & $\begin{array}{c}\text { Money Market } \\
\text { Services/Bloomberg } \\
\text { Identifiers }\end{array}$ & $\begin{array}{l}\text { Historical } \\
\text { Standard Dev. } \\
\text { of Surprises }\end{array}$ \\
\hline $\begin{array}{l}\text { Consumer Price Index } \\
\text { (preliminary) }\end{array}$ & $\begin{array}{l}\text { pct. change from } \\
\text { previous month }\end{array}$ & $\begin{array}{c}\text { GECPIM, } \\
\text { GRCPIPMM } \\
\text { GRCP20MM }\end{array}$ & 0.11 percentage points \\
\hline Real GDP (preliminary) & $\begin{array}{l}\text { pct. change from } \\
\text { previous quarter }\end{array}$ & $\begin{array}{l}\text { GEGDPPGQ, } \\
\text { GRGDPPGQ }\end{array}$ & 0.16 percentage points \\
\hline $\begin{array}{l}\text { IFO Business Climate } \\
\text { Conditions Survey }\end{array}$ & index & $\begin{array}{l}\text { GEIFOBC, } \\
\text { GRIFBUS }\end{array}$ & 1.24 index points \\
\hline Retail Sales & $\begin{array}{l}\text { pct. change from } \\
\text { previous month }\end{array}$ & $\begin{array}{l}\text { GERETAILM, } \\
\text { GRFRIAMM }\end{array}$ & 2.17 percentage points \\
\hline Unemployment Claims & $\begin{array}{c}\text { change from prev. } \\
\text { month (000s) }\end{array}$ & $\begin{array}{l}\text { GEUNEMPC, } \\
\text { GRUECHNG }\end{array}$ & 28.5 thousand workers \\
\hline
\end{tabular}

Table A3. Details of major German macroeconomic announcements included in our regression analysis. Historical standard deviation of surprises is for the period 1995-2012. See text for details.

the longest history and the largest number of forecasters in the MMS and Bloomberg surveys.

For Germany, the MMS survey data for most series do not begin until about 1995 or 1996. In addition, although East and West Germany were officaly reunified in 1990, German statistical agencies did not start reporting data for unified Germany until about 1995 in most cases. Thus, our sample for Germany begins in 1995.

As for the U.S. and U.K., both MMS and Bloomberg collect data on other major German macroeconomic series than those listed in Table A3 (such as industrial production and a producer price index, among others), but these did not have a statistically significant effect on either German or U.K. interest rates or exchange rates. Although it seems surprising that so few German macroeconomic data releases would have a significant on German interest rates, this finding has also been reported by other authors (e.g., Andersson et al., 2006, Ehrmann et al., 2011). One often-cited explanation is that German macroeconomic data are released with a longer lag than U.S. macroeconomic data, and thus the German data have a lower information content than the corresponding U.S. releases. If the U.S. data serve as good leading indicators for the future values of the German data, that could also help to explain why German bonds respond more to U.S. macroeconomic announcements than to domestic announcements (see Table 4 in the main text). 

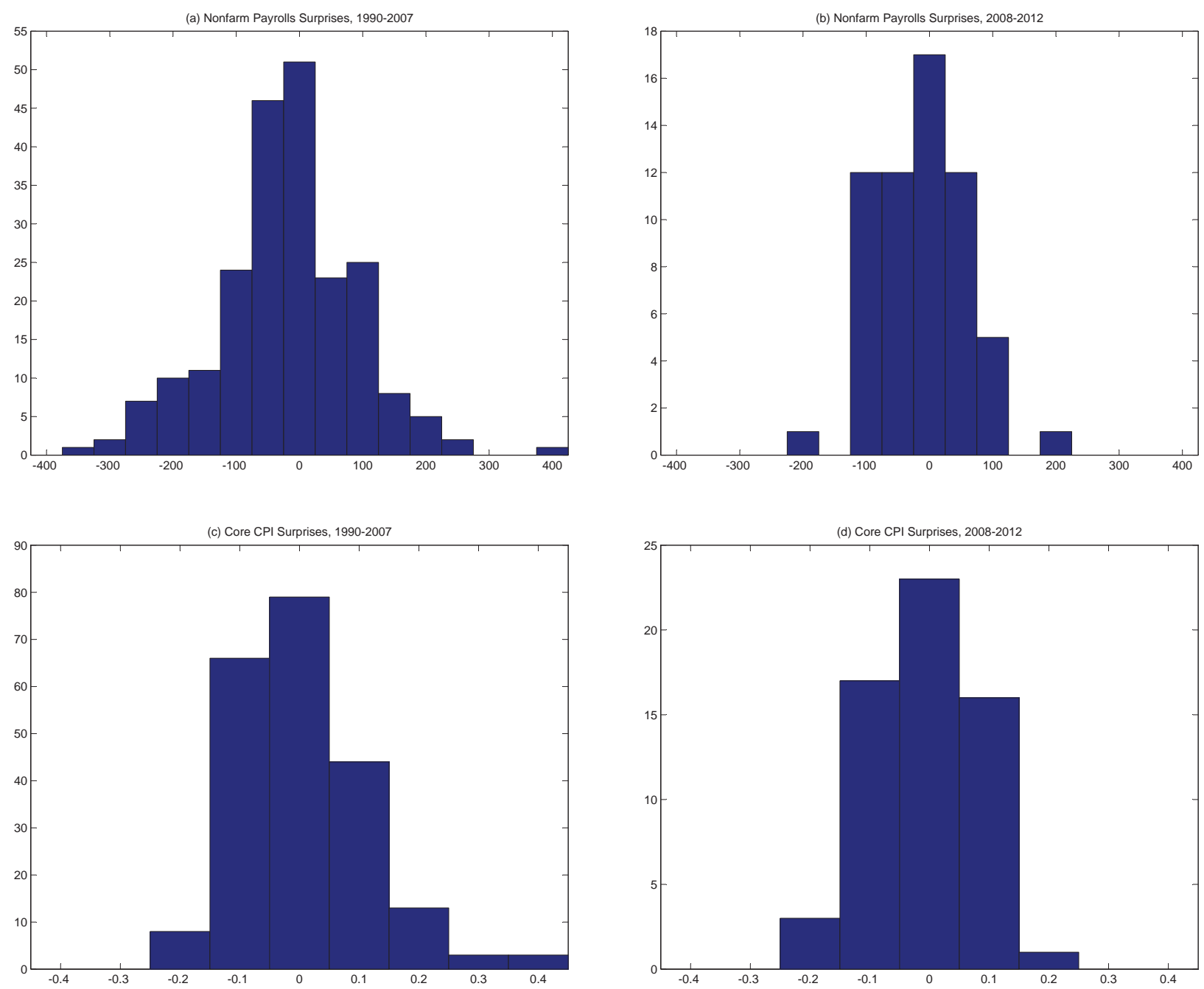

Figure A1. Top panels depict empirical distribution of the surprise component of U.S. nonfarm payrolls announcements from (a) 1990-2007 and (b) 2008-12, rounded to the nearest 50 thousand workers. Bottom panels depict the distribution of U.S. core CPI surprises from (c) 1990-2007 and (d) 2008-12, rounded to the nearest 0.1 percent. The surprise distributions of these and other macroeconomic data releases are relatively similar pre- and post-crisis. See text for details.

\section{A.2 Distribution of Macroeconomic Data Surprises Pre- and Post-2008}

In our main empirical regressions (10) and (11), the surprise component of each data release in $X_{t}$ can be regarded as strictly exogenous, under the assumption that our survey expectations data incorporate all relevant information as of the day before the release. (Under this assumption, the surprise component of each data release is independent of all past and future values of the interest rate changes on the left-hand side of these regressions.) To the extent that regressions (10) and (11) are correctly specified, strict exogeneity then implies that the empirical distribution of the 
macroeconomic surprise data $X_{t}$ is irrelevant for our estimates of the relative response coefficients $\beta$ or time-varying sensitivity coefficients $\delta$.

Nevertheless, one might be concerned that regression specifications (10) and (11) are simplifications that assume a linear structure with respect to $X_{t}$. As a result, it would be reassuring if the distribution of data surprises $X_{t}$ in 2008-12 was not dramatically different from our benchmark sample from the mid-1990s to 2000, or to 2007.

In fact, the distribution of these macro data surprises is similar across these samples. This can be seen in Figure A1, which plots the surprise component of U.S. nonfarm payrolls and U.S. core CPI announcements over the 1990-2007 and 2008-12 periods. Results for other macroeconomic data releases and the 1990-2000 period are similar. This finding might seem puzzling at first given the severity of the 2007-09 recession, but one should bear in mind that financial markets were quick to realize the severity of the downturn, so financial market expectations of the data fell about in line with the decline in the data itself. As a result, the surprises in the data releases, relative to the one-day-ahead expectations, do not look very different from earlier periods. 


\section{References}

Altig, David, Lawrence J. Christiano, Martin Eichenbaum, and Jesper Lindé (2011). "Firm-Specific Capital, Nominal Rigidities, and the Business Cycle," Review of Economic Dynamics 14, 225247.

Andersen, Torben G., Tim Bollerslev, Francis X. Diebold, and Clara Vega (2003). "Micro Effects of Macro Announcements: Real-Time Price Discovery in Foreign Exchange," American Economic Review 93(1), 38-62.

Andersson, Magnus, Lars Jul Hansen, and Szabolcs Sebestyén (2006). "Which News Moves the Euro Area Bond Market?" European Central Bank Working Paper Series 631.

Bernanke, Ben S., and Vincent R. Reinhart (2004). "Conducting Monetary Policy at Very Low Short-Term Interest Rates," American Economic Review, Papers and Proceedings 94(2), 85-90.

Bernanke, Ben S., Vincent R. Reinhart, and Brian P. Sack (2004). "Monetary Policy Alternatives at the Zero Bound: An Empirical Assessment," Brookings Papers on Economic Activity, Fall, $1-78$.

Chan, K.C., G. Andrew Karolyi, Francis Longstaff, and Anthony Sanders (1992). "An Empirical Comparison of Alternative Models of the Short-Term Interest Rate," Journal of Finance 47, $1209-1227$.

Christensen, Jens, and Glenn Rudebusch (2012). "The Response of Interest Rates to US and UK Quantitative Easing," Economic Journal 122, F385-F414.

Christiano, Lawrence, Martin Eichenbaum, and Sergio Rebelo (2011). "When is the Government Spending Multiplier Large?" Journal of Political Economy 119, 78-121.

Clarida, Richard, Jordi Galí, and Mark Gertler (2002). "A Simple Framework for International Monetary Policy Analysis," Journal of Monetary Economics 49, 879-904.

DeLong, J. Bradford and Lawrence Summers (2012). "Fiscal Policy in a Depressed Economy," Brookings Papers on Economic Activity, Spring, 233-274.

Eggertsson, Gauti B. (2009). "What Fiscal Policy is Effective at Zero Interest Rates?" Federal Reserve Bank of New York Staff Report 402.

Eggertsson, Gauti B., and Paul Krugman (2012). "Debt, Deleveraging, and the Liquidity Trap: A Fisher-Minsky-Koo Approach," Quarterly Journal of Economics 127, 1469-1513.

Eggertsson, Gauti B., and Michael Woodford (2003). "The Zero Interest-Rate Bound and Optimal Monetary Policy," Brookings Papers on Economic Activity, Spring, 139-211.

Ehrmann, Michael, Marcel Fratzscher, Refet S. Gürkaynak, and Eric T. Swanson (2011). "Convergence and Anchoring of Yield Curves in the Euro Area," Review of Economics and Statistics 93, 350-364.

Engel, Charles (2013). "Exchange Rates and Interest Parity," Handbook of International Economics, forthcoming.

Erceg, Christopher J., and Jesper Lindé (2010). "Is There a Fiscal Free Lunch in a Liquidity Trap?" Federal Reserve Board International Finance Discussion Paper 2010-1003.

Faust, Jon, John H. Rogers, Shing-Yi B. Wang, and Jonathan H. Wright (2007). "The HighFrequency Response of Exchange Rates and Interest Rates to Macroeconomic Announcements," Journal of Monetary Economics 54, 1051-1068. 
Gagnon, Joseph, Matthew Raskin, Julie Remache, and Brian Sack (2011). "The Financial Market Effects of the Federal Reserves Large-Scale Asset Purchases." International Journal of Central Banking 7(1), 3-43.

Glick, Reuven and Sylvain Leduc (2013). "The Effects of Unconventional and Conventional U.S. Monetary Policy on the Dollar," manuscript, Federal Reserve Bank of San Francisco.

Gürkaynak, Refet S., Andrew Levin, and Eric Swanson (2010). "Does Inflation Targeting Anchor Long-Run Inflation Expectations? Evidence from the U.S., UK, and Sweden," Journal of the European Economic Association 8(6), 1208-1242.

Gürkaynak, Refet S., Brian Sack, and Eric T. Swanson (2005a). "Do Actions Speak Louder than Words? The Response of Asset Prices to Monetary Policy Actions and Statements," International Journal of Central Banking 1(1), 55-93.

Gürkaynak, Refet S., Brian Sack, and Eric Swanson (2005b). "The Sensitivity of Long-Term Interest Rates to Economic News: Evidence and Implication for Macroeconomic Models." American Economic Review 95(1), 426-436.

Gürkaynak, Refet S., Brian Sack, and Jonathan H. Wright (2007). "The U.S. Treasury Yield Curve: 1961 to the Present," Journal of Monetary Economics 54, 2291-2304.

Hamilton, James, and Jing (Cynthia) Wu (2012). "The Effectiveness of Alternative Monetary Policy Tools in a Zero Lower Bound Environment," Journal of Money, Credit, and Banking 44(S1), $3-46$.

Joyce, Michael, Ana Lasaosa, Ibrahim Stevens, and Matthew Tong (2011). "The Financial Market Impact of Quantitative Easing," International Journal of Central Banking 7(3), 113-161.

Krishnamurthy, Arvind, and Annette Vissing-Jorgensen (2011). "The Effects of Quantitative Easing on Interest Rates: Channels and Implications for Policy," Brookings Papers on Economic Activity, Fall, 215-265.

Krishnamurthy, Arvind, and Annette Vissing-Jorgensen (2012). "The Aggregate Demand for Treasury Debt," Journal of Political Economy 120, 233-267.

Kuttner, Kenneth N. (2001). "Monetary policy surprises and interest rates: Evidence from the Fed funds futures market." Journal of Monetary Economics 47(3), 523-544.

Modigliani, Franco, and Richard Sutch (1966). "Innovations in Interest Rate Policy," American Economic Review 56(1), 178-197.

Reifschneider, David, and John C. Williams (2000). "Three Lessons for Monetary Policy in a Low Inflation Era," Journal of Money, Credit and Banking 32(4), 936-966.

Sack, Brian, and Volker Wieland (2000). "Interest-Rate Smoothing and Optimal Monetary Policy: A Review of Recent Empirical Evidence," Journal of Economics and Business 52, 205-228.

Sims, Christopher A., and Tao Zha (1999). "Error Bands for Impulse Responses," Econometrica 67(5), 1113-1155.

Swanson, Eric T. (2006). "Have Increases in Federal Reserve Transparency Improved Private Sector Interest Rate Forecasts?" Journal of Money, Credit, and Banking 38, 791-819.

Swanson, Eric T. (2011). "Let's Twist Again: A High-Frequency Event-Study Analysis of Operation Twist and Its Implications for QE2," Brookings Papers on Economic Activity, Spring, 151-188.

Swanson, Eric T., and John C. Williams (2013). "Measuring the Effect of the Zero Lower Bound on Medium- and Longer-Term Interest Rates," Federal Reserve Bank of San Francisco Working Paper 2012-02. 
Taylor, John (1993). "Discretion Versus Policy Rules in Practice," Carnegie-Rochester Conference Series on Public Policy 39, 195-214.

Tobin, James (1958). "Liquidity Preference as Behavior Toward Risk," Review of Economic Studies $25,124-131$.

Vayanos, Dimitri, and Jean-Luc Vila (2009). "A Preferred-Habitat Model of the Term Structure of Interest Rates," NBER Working Paper 15487.

Woodford, Michael (2003). Interest and Prices: Foundations of a Theory of Monetary Policy, Princeton: Princeton University Press.

Woodford, Michael (2011). "Simple Analytics of the Government Expenditure Multiplier," American Economic Journal: Macroeconomics 3, 1-35. 